\title{
Los consumidores ante las plataformas de intermediación Online: algunas reflexiones
}

\section{Reflections on Consumers Facing Online: Intermediation Platforms}

Jorge Tomillo Urbina (*) https://orcid.org/0000-0003-4369-5116

http://dx.doi.org/10.21503/lex.v19i27.2252

* Catedrático de Derecho Mercantil y Director del Departamento de Derecho Privado (Universidad de Cantabria, España). Doctor en Derecho summa cum laude por la Universidad de Alcalá de Henares. Doctor Honoris Causa por la Universidad Autónoma de Santo Domingo (Primada de América), Director de la Cátedra Euroamericana de Protección Jurídica de los Consumidores, Presidente de la Junta Arbitral de Consumo de la Comunidad Autónoma de Cantabria. España.

Correo electrónico: jorge.tomillo@unican.es

El presente trabajo se ha desarrollado en ejecución del proyecto titulado "Fomento de la investigación en materia de consumo 2020", financiado por la Consejería de Innovación, Industria, Transporte y Comercio del Gobierno de Cantabria.

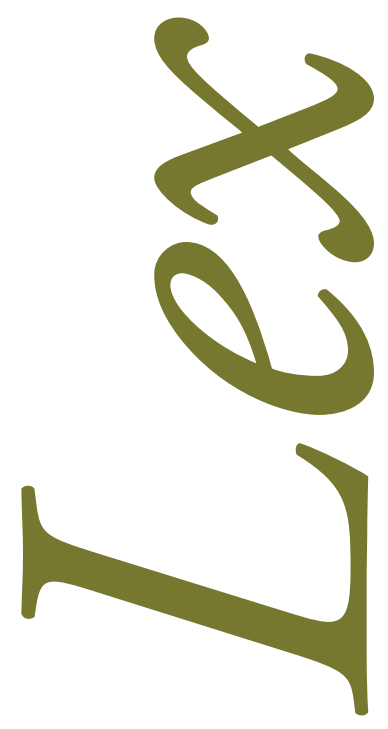




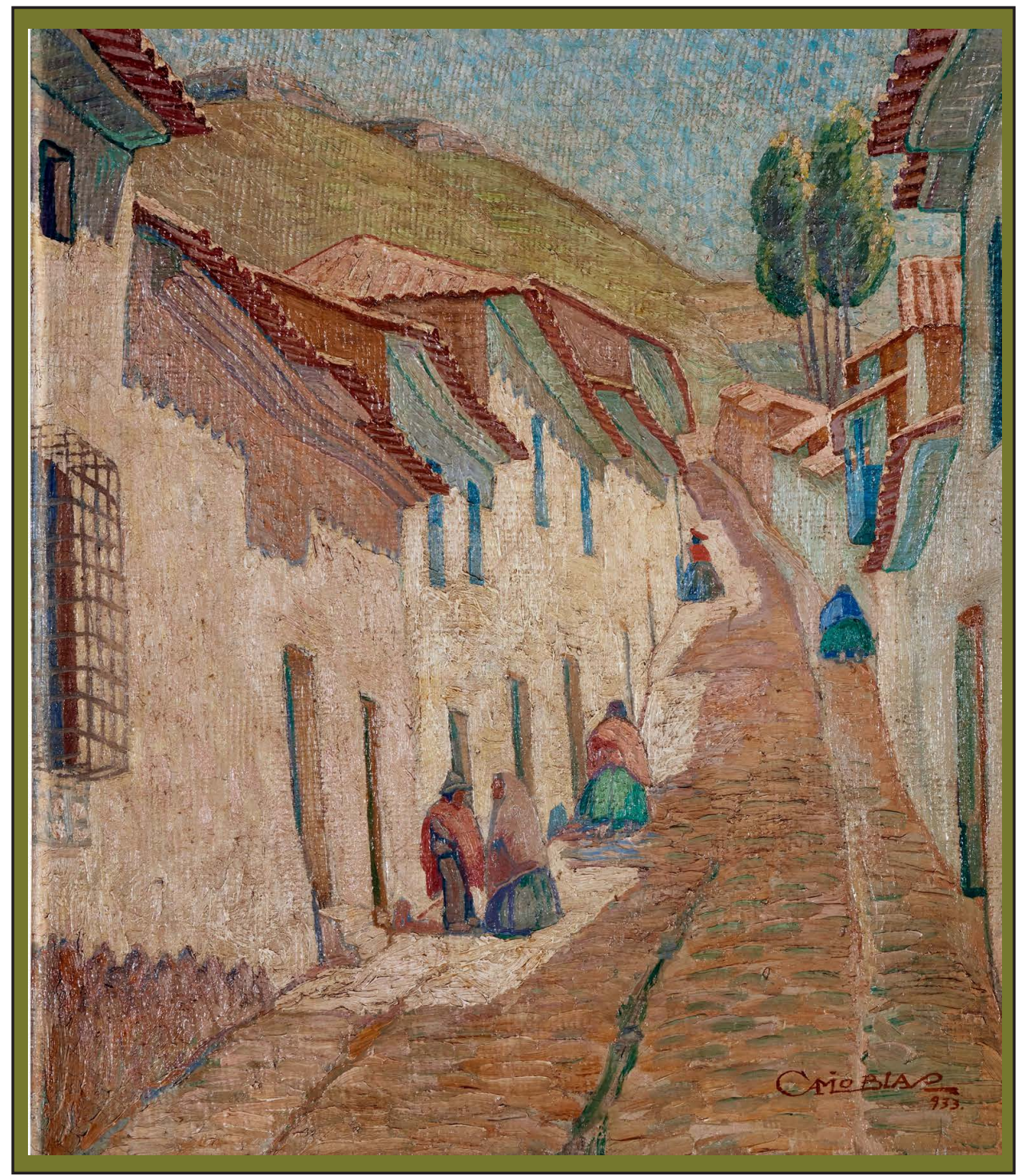

Cuesta de Pumacurco. Camilo Blas pintor peruano del indigenismo (Cajamarca 1903-1985). 


\section{RESUMEN}

El trabajo versa sobre la irrupción de las plataformas digitales en la contratación con consumidores desarrollando fórmulas de consumo colaborativo, pero también suscitando problemas y dificultades como consecuencia de la especial vulnerabilidad de los consumidores en línea, especialmente cuando contratan con otros consumidores-proveedores (prosumidores), decayendo las herramientas de protección dispuestas para la tutela de las posiciones jurídicas asimétricas. Se analiza la variabilidad del concepto de consumidor enunciando y desarrollando la prevalencia del principio de ajenidad en situaciones complejas con el propósito de diseccionar la normativa europea en materia de equidad y transparencia de los servicios de intermediación en línea de examinar y proponer diversas técnicas para la protección jurídica de los usuarios no profesionales.

Palabras clave: Plataformas de intermediación en línea, proveedores del mercado en línea, consumidores, usuarios, prosumidores, transparencia, equidad, reseñas de los clientes, decisiones automatizadas, algoritmos de buisqueda, ocultación de información, responsabilidad del prestador.

\section{ABSTRACT}

This study delves into the emergence of digital platforms in contracting with consumers, developing collaborative consumption formulas. However, the piece also touches on the raising problems and difficulties that have surged as a consequence of the special vulnerability of online consumers, especially when they contract with other consumer-providers (prosumers), thus bringing forth a steep decline in the array of protection tools available for the tutelage of asymmetric legal positions. The variability of the concept of consumer is analyzed by stating and developing the prevalence of the principle of alienation in complex situations with the purpose of dissecting European regulations on fairness and transparency of online intermediation services. The work concludes by examining and proposing various techniques for the legal protection of non-professional users.

Key words: Online intermediation platforms, online market providers, consumers, users, prosumers, transparency, fairness, customer reviews, automated decisions, search algorithms, information concealment, provider liability. 


\section{INTRODUCCIÓN}

\section{LA ECONOMÍA DE LAS PLATAFORMAS}

Recientemente se ha acuñado el término de capitalismo de las plataformas ${ }^{l}$ para designar una de las profundas transformaciones que nacen en los últimos tiempos, explicando cómo, en los albores del siglo XXI, sobre la base de los formidables cambios producidos en el desarrollo de las tecnologías digitales, los datos se han vuelto cada vez más centrales para las empresas y su relación con trabajadores, clientes y otros capitalistas (stakeholders). La plataforma emergió como un nuevo modelo de negocio capaz de extraer y controlar una inmensa cantidad de datos y, al calor de este cambio, se ha impulsado el ascenso de grandes compañías monopólicas. Hoy en día el capitalismo de las economías de altos y medianos ingresos está dominado cada vez más por estas empresas, que ejercen una función cada vez más importante en las adquisiciones de consumo e, incluso, en su financiación.

\section{LAS PLATAFORMAS DIGITALES Y EL CONSUMO COLABORATIVO: REALIDADES Y DESAFÍOS DE UN SISTEMA}

En términos generales, podemos entender consumo colaborativo como la actividad propia de un conjunto de sistemas de circulación de recursos que permiten a los consumidores obtener y proporcionar, de manera temporal o permanente, productos o servicios valiosos a través de interacción con otros consumidores o a través de un mediador. Se establece así una diferencia central respecto del consumo convencional, entendido como un sistema de distribución de recursos que involucra a consumidores pasivos (no proveedores), que no pueden o no tienen la capacidad de proporcionar ningún recurso o servicio. Incapaces de participar en la obtención o en la provisión, su papel está limitado a comprar y consumir recursos $^{2}$ de manera intuitiva (no profesional).

1. Nick Srnizek, Platform Capitalism, Cambridge (UK)/Malden, MA (USA), Polity Press, 2017: 6.

2. Myriam Ertz, Fabien Durif y Manon Arcand: “Collaborative consumption: conceptual snapshot at a buzzword”, Journal of Entrepreneurship Education, 19.2 (2016): 1-3. 
El consumo colaborativo se refiere a todos aquellos sistemas de distribución de recursos que permiten al consumidor ser el adquirente o el proveedor de un recurso (C2C). El ecosistema donde se desarrolla el consumo colaborativo está marcado por las plataformas digitales, que establecen un marco en el que los usuarios pueden interactuar entre ellos ${ }^{3}$ y con la misma plataforma desarrollando sistemas comerciales de mutualización peer-to-peer (P2P). Los usuarios seleccionan la función que desean en cada momento, o varios roles simultáneamente (v.gr.: vendedor y comprador). Las plataformas actúan como intermediarios on line que coordinan diferentes tipos de usuarios para permitir la interacción económica o social ${ }^{4}$.

3. La estructura y funcionalidad de las plataformas digitales es variada, como diversa es también la forma de abordar su casuística por la jurisprudencia europea. Vid. la STJUE (Gran Sala) de 19 de diciembre de 2019 (asunto C-390/18) [ECLI:EU:C:2019:336] declarando que la plataforma Airbnb no es un prestador profesional de servicios de alojamiento sino que, por el contrario, su objeto prestacional son servicios de intermediación de la sociedad de la información prestados a cambio de una remuneración, cuyo objeto es poner en contacto mediante una plataforma electrónica a potenciales arrendatarios con arrendadores: "El artículo 2, letra a), de la Directiva 2000/31/CE del Parlamento Europeo y del Consejo, de 8 de junio de 2000, relativa a determinados aspectos jurídicos de los servicios de la sociedad de la información, en particular el comercio electrónico en el mercado interior [...], debe interpretarse en el sentido de que procede calificar de «servicio de la sociedad de la información» comprendido en el ámbito de aplicación de la Directiva 2000/31/CE un servicio de intermediación, prestado a cambio de una remuneración, que tiene por objeto poner en contacto mediante una plataforma electrónica a potenciales arrendatarios con arrendadores, profesionales o no profesionales, que proponen servicios de alojamiento de corta duración y que, además, ofrece otras prestaciones accesorias de ese servicio de intermediación". Anteriormente, sin embargo, la STJUE (Gran Sala) de 20 de diciembre de 2017 (asunto C-434/15) [EU:C:2017:981], había negado la condición de prestador de servicios de la sociedad de la información a la plataforma Uber en el entendimiento de que, a pesar de que un servicio de intermediación consistente en conectar a un conductor no profesional que utiliza su propio vehículo con una persona que desea realizar un desplazamiento urbano constituye, en principio, un servicio distinto del servicio de transporte (que consiste en el acto físico de desplazamiento de personas o bienes de un lugar a otro mediante un vehículo), hay que tener en cuenta que "sin la aplicación proporcionada por Uber, ni los conductores estarían en condiciones de prestar servicios de transporte ni los clientes podrían recurrir a los servicios de los conductores". Añade además el TJUE que la plataforma digital Uber ejerce una influencia decisiva sobre las condiciones de las prestaciones efectuadas por estos conductores. "Consta en particular que Uber, mediante la aplicación epónima, establece al menos el precio máximo de la carrera, que recibe este precio del cliente para después abonar una parte al conductor no profesional del vehículo y que ejerce cierto control sobre la calidad de los vehículos, así como sobre la idoneidad y el comportamiento de los conductores, lo que en su caso puede entrañar la exclusión de éstos". Por ello concluye: "debe considerarse que este servicio de intermediación forma parte integrante de un servicio global cuyo elemento principal es un servicio de transporte y, por lo tanto, que no responde a la calificación de «servicio de la sociedad de la información", en el sentido del artículo 1, punto 2, de la Directiva 98/34, al que remite el artículo 2, letra a), de la Directiva 2000/31, sino a la de «servicio en el ámbito de los transportes», en el sentido del artículo 2, apartado 2, letra d), de la Directiva 2006/123". Vid. el post de Jesús Alfaro Águila-Real: “La sentencia Uber del TJUE”, en El Almacén de Derecho, 20 de diciembre de 2017, y, desde otra óptica, el de Ignacio Gomá Garcés y Pablo Ojeda Baños: "HD Joven: a propósito de la reciente sentencia del TJUE sobre Uber", en Hay Derecho, 16 de febrero de 2018. Más extensamente sobre el tema, vid. el interesante y documentado estudio de Matilde Cuena Casas: "La contratación a través de plataformas intermediarias en línea”, en Cuadernos de Derecho Transnacional (octubre 2020), vol. 12, n 2: 304-309 \$\$ 56-77.

4. Jonathan D. Levin: "The economics of internet markets", National Bureau of Economic Research, Massachusetts, (2011), passim. 
Se trata de un sistema abierto y dinámico que marca un cambio de paradigma ${ }^{5}$ integrando un mecanismo de evaluación entre usuarios, mediante el que adquieren una reputación y, con ella, la confianza necesaria para seguir llevando a cabo la actividad que deseen, con opciones de mejora. Lógicamente, cuanto mayor sea el número de usuarios que exista en la plataforma digital, más valor tendrá la misma, los usuarios tendrán más posibilidades de elección y promoción, serán mejor evaluados y la confianza estará más contrastada.

Buena prueba de la relevancia que adquiere la incorporación de las nuevas tecnologías digitales a la contratación privada, es la reciente aprobación del Reglamento (UE) 2019/1150 del Parlamento Europeo $y$ del Consejo, de 20 de junio de 2019, sobre el fomento de la equidad y la transparencia para los usuarios profesionales de servicios de intermediación en línea ${ }^{6}$, que será de aplicación directa a partir del 12 de julio de 2020 (art. 19.2). El texto toma esta relevancia como punto de partida ${ }^{7}$ :

"Los servicios de intermediación en línea son factores esenciales para el emprendimiento y los nuevos modelos de negocio, el comercio y la innovación que, a su vez, también pueden potenciar el bienestar de los consumidores y cada vez se emplean más tanto en el sector privado como en el público. Facilitan el acceso a nuevos mercados y oportunidades comerciales de modo que permiten a las empresas aprovechar las ventajas del mercado interior. Permiten a los consumidores de la Unión obtener provecho de dichas ventajas, en concreto al ampliar la gama de bienes y servicios y al contribuir a la oferta de precios competitivos en línea, pero también plantean desafíos a los que hay que hacer frente si se quiere garantizar la seguridad jurídica".

En el ámbito de los desafíos que plantea la contratación intermediada por plataformas digitales, el Reglamento (UE) 2019/1150 introduce la necesidad de prevenir la imposición unilateral de prácticas considerablemente desviadas de las buenas conductas comerciales o contrarias a la buena fe y a la lealtad que debe inspirar las relaciones comerciales, con perjuicio también para los consumidores de la Unión, que podrían ser víctimas de comportamientos injustos asentados en su asimetría posicional ${ }^{8}$ :

"Los servicios de intermediación en línea pueden ser cruciales para el éxito comercial de las empresas que los utilizan para llegar a los consumidores. Por tanto, a fin de aprovechar plenamente las ventajas de la economía de plataformas en línea, es importante que las empresas puedan confiar en los servicios de intermediación en línea con los que entablan relaciones comerciales. Esta importancia reside principalmente en que la creciente intermediación de las transacciones a través de servicios en línea, fortalecida por potentes efectos de red indirectos basados en datos, conduce a que los usuarios profesionales - incluidas las microempresas y las pequeñas y medianas empresas — dependan cada vez más de tales servicios para llegar a los consumidores.

5. Vid. Matilde Cuena Casas: “La contratación” cit., en Cuadernos de Derecho Transnacional (octubre 2020): $288 \$ 6$.

6. DOUE núm. 186, de 11 de julio de 2019, ref. DOUE-L-2019-81157.

7. Considerando (1).

8. Considerando (2). 
A causa de esa dependencia cada vez mayor, los proveedores de los servicios de intermediación en línea a menudo cuentan con una superior capacidad de negociación, lo que les permite, en efecto, actuar unilateralmente de una manera que puede ser injusta y perjudicar a los intereses legitimos de los usuarios profesionales y, de modo indirecto, también de los consumidores de la Unión. Por ejemplo, podrían imponer unilateralmente a los usuarios profesionales prácticas que se desvían considerablemente de las buenas conductas comerciales o son contrarias a la buena fe y a la lealtad de las relaciones comerciales. El presente Reglamento da respuesta a esas posibles fricciones en la economía de plataformas en línea”.

Sin embargo, el Reglamento, como insistiremos más adelante, se centra en el fomento de la equidad y transparencia para los usuarios profesionales de servicios de intermediación en línea (B2C), considerando tan solo indirectamente los perjuicios que podrían derivarse para los consumidores y usuarios que acuden a dichas plataformas on line. En este contexto, es frecuente que personas completamente ajenas a cualquier actividad de empresa, comercio, oficio o profesión, no se limiten a aplicar sus rentas de trabajo personal a la adquisición de productos de consumo para la satisfacción de sus necesidades personales, familiares o domésticas, sino que, además, actúen como proveedores de productos y servicios (Ebay, Wallapop, Blablacar).

Esta realidad tiene consecuencias importantes en el régimen jurídico aplicable a dichas transacciones, hasta el punto de que los compradores que adquieren bienes suministrados por un proveedor no profesional $(\mathrm{C} 2 \mathrm{C})$ pueden experimentar, sin advertencia previa, una rebaja sustancial de las técnicas de protección que acompañan a esas mismas adquisiciones en un mercado tradicional de proveedores minoristas profesionales?.

\section{LA CONDICIÓN JURÍDICA DE CONSUMIDOR: EL PRINCIPIO DE AJENIDAD}

En efecto, pensemos que el acervo principal de protección jurídica de los intereses patrimoniales de los contratantes vulnerables -no profesionales- por su asimetría posicional respecto de los proveedores profesionales, viene contenido en el Real Decreto Legislativo 1/2007, de 16 de noviembre, por el que se aprueba el texto refundido de la Ley General para la Defensa de los Consumidores y Usuarios (TRLGDCU), que establece como leyenda de frontispicio su propio ámbito subjetivo de aplicación: "[e]sta norma será de aplicación a las relaciones entre consumidores o usuarios y empresarios" (art. 2).

9. Vid. la Ley 7/1996, de 15 de enero, de Ordenación del Comercio Minorista, cuyo artículo 1.2 establece: “[a] los efectos de la presente Ley, se entiende por comercio minorista aquella actividad desarrollada profesionalmente con ánimo de lucro consistente en ofertar la venta de cualquier clase de artículos a los destinatarios finales de los mismos, utilizando o no un establecimiento". 
A este presupuesto subjetivo de naturaleza vertical (B2C), ha de añadirse el condicionante objetivo que activa la aplicación del sistema proteccionista: "[l]os poderes públicos protegerán prioritariamente los derechos de los consumidores y usuarios cuando guarden relación directa con bienes o servicios de uso o consumo común, ordinario y generalizado" (art. 9).

En relación con el concepto de consumidor, el artículo 3 TRLGDCU sustituye el viejo criterio del destino final ${ }^{10}$ por el más moderno de la ajenidad ${ }^{11}$ a cualquier tipo de actividad de naturaleza profesional: "[...] son consumidores o usuarios las personas fisicas que actúen con un propósito ajeno a su actividad comercial, empresarial, oficio o profesión. Son también consumidores [...] las personas jurídicas y las entidades sin personalidad jurídica que actúen sin ánimo de lucro en un ámbito ajeno a una actividad comercial o empresarial'.

En consecuencia, existirá un acto de consumo cuando un consumidor contrate con un empresario, entendiendo por tal "[...] toda persona física o jurídica, ya sea privada o pública, que actúe directamente o a través de otra persona en su nombre o siguiendo sus instrucciones, con un propósito relacionado con su actividad comercial, empresarial, oficio o profesión" (art. 4), y el TRLGDCU desplegará todos sus efectos cuando, además, el objeto de la relación jurídica guarde relación directa con bienes o servicios de uso o consumo común, ordinario y generalizado ${ }^{12}$.

\section{PREVALENCIA DEL PRINCIPIO DE AJENIDAD EN SITUACIONES COMPLEJAS}

Lo anteriormente expuesto nos lleva a realizar algunas consideraciones previas en relación con el concepto jurídico de consumidor y el comportamiento de su tipicidad ante determinadas situaciones que podemos considerar complejas, ya sea atendiendo a la concurrencia ocasional de una intención lucrativa, ya sea atendiendo a la utilización por el consumidor -de manera fragmentaria- de técnicas propias de la actividad profesional, ya sea por la aplicación del uso de los bienes con fines mixtos, ya sea, en fin, por la prestación -muy frecuente en la práctica de los profesionales autónomos y de las pequeñas empresas- de garantías no profesionales para asegurar operaciones empresariales.

10. Contemplado en el artículo 1.2 y 3 de la derogada Ley 26/1984, de 19 de julio, General para la Defensa de los Consumidores y Usuarios.

11. Sobre esta cuestión, vid., por todos, el excelente y extenso análisis realizado por Joaquín Cayón de las Cuevas: $L a$ prestación de servicios sanitarios como relación jurídica de consumo, ed. Civitas-Thomson Reuters, Cizur Menor, 2017: 145 y ss., especialmente pp. 179-196, donde acuña la expresión “ajenidad de propósito empresarial” (p. 180). Puede verse también María José Reyes López: "La reforma introducida en el TRLGDCU por Ley 3/2014 sobre el derecho de desistimiento e información”, Actualidad Jurídica Iberoamericana, 2 (2015): 258.

12. Vid. Anexo I del Real Decreto 1507/2000, de 1 de septiembre, por el que se actualizan los catálogos de productos y servicios de uso o consumo común, ordinario y generalizado y de bienes de naturaleza duradera (vid. Disposición transitoria segunda TRLGDCU). 


\section{IV.1. AJENIDAD Y ÁNIMO DE LUCRO}

La jurisprudencia europea y española establecen de forma terminante la prevalencia de la condición jurídica de consumidor incluso en aquellos casos en que el consumidor persona física actúe con ánimo de lucro, elemento intencional característico de las transacciones económicas profesionales que, sin embargo, no es suficiente para excluir per se la condición jurídica de consumidor con carácter general. Para mantener la prevalencia de esta condición es requisito imprescindible que no concurra la nota de habitualidad en el ejercicio de la operación (ejercicio regular), lo que reclamaría la aplicación del estatuto profesional.

La existencia de ánimo de lucro es circunstancia excluyente de la condición jurídica de consumidor (requisito negativo) únicamente para las personas jurídicas, como establece la STS núm. 16/2017, de 16 de enero $^{13}$ (FD 20):

“[... la reforma del mencionado art. 3 TRLGCU por la Ley 3/2014, de 27 de marzo [...] puede arrojar luz sobre la cuestión. En efecto, a diferencia de lo que ocurre con las directivas comunitarias que sólo se refieren a personas físicas, tras dicha reforma se sigue distinguiendo entre consumidor persona física y consumidor persona jurídica, pero se añade que el ánimo de lucro es una circunstancia excluyente solo en el segundo de los casos. Es decir, se introduce un requisito negativo únicamente respecto de las personas jurídicas, de donde cabe deducir que la persona fisica que actúa al margen de una actividad empresarial es consumidora, aunque tenga ánimo de lucro.

No obstante, sin apartarse de dicha regulación, cabría considerar que el ánimo de lucro del consumidor persona física debe referirse a la operación concreta en que tenga lugar, puesto que si el consumidor puede actuar con afán de enriquecerse, el límite estará en aquellos supuestos en que realice estas actividades con regularidad (comprar para inmediatamente revender sucesivamente inmuebles, acciones, etc.), ya que de realizar varias de esas operaciones asiduamente en un período corto de tiempo, podría considerarse que, con tales actos, realiza una actividad empresarial o profesional, dado que la habitualidad es una de las características de la cualidad legal de empresario, conforme establece el art. 1.1º del Código de comercio.

Desde este punto de vista, no consta que la Sra. Milagrosa realizara habitualmente este tipo de operaciones, por lo que la mera posibilidad de que pudiera lucrarse con el traspaso o reventa de sus derechos no excluye su condición de consumidora".

En este mismo sentido, la Sentencia del Tribunal de Justicia de la Unión Europea (Sala Sexta) de 10 de diciembre de 2020 (asunto C-774/19) ${ }^{14}$, ha declarado que una persona física domiciliada en un Estado miembro que, por una parte, ha celebrado con una sociedad establecida en otro Estado miembro un contrato para jugar al póker en Internet que contiene condiciones generales determinadas por esta últi-

13. Recurso núm. 2718/2014.

14. ECLI:EU:C:2020:1015. 
ma y, por otra parte, a) no ha declarado oficialmente tal actividad y b) no ha ofrecido dicha actividad a terceros como servicio de pago, no pierde la condición jurídica de consumidor a efectos de esta disposición ${ }^{15}$ aunque dedique a ese juego un gran número de horas al día (una media de nueve horas diarias por día laborable), posea amplios conocimientos y obtenga de dicho juego considerables ganancias ${ }^{16}$. El tribunal europeo va ahora un poco más lejos, ya que no parece tarea fácil justificar la exclusión de la nota de habitualidad (regularidad) en una dedicación cotidiana tan intensa ${ }^{17}$.

\section{IV.2. AJENIDAD Y CONTRATOS CON DOBLE FINALIDAD}

La condición jurídica de consumidor no va ligada a ningún "atributo" subjetivo, sino más bien a la posición que ocupa una persona en un contrato determinado de acuerdo con la naturaleza y finalidad de éste. En este sentido, la STS núm. 548/2018, de 5 de octubre ${ }^{18}$ (FD 20) establece que:

“[E]l concepto de «consumidor» debe interpretarse en relación con la posición de esta persona en un contrato determinado y con la naturaleza y la finalidad de éste, y no con la situación subjetiva de dicha persona, dado que una misma persona puede ser considerada consumidor respecto de ciertas operaciones y operador económico respecto de otras. De tal forma que, solo a los contratos celebrados fuera e independientemente de cualquier actividad o finalidad profesional, con el único objetivo de satisfacer las propias necesidades de consumo privado de un individuo, les es de aplicación el régimen especifico establecido para la protección del consumidor como parte considerada económicamente más débil, mientras que esta protección no se justifica en el caso de contratos cuyo objeto consiste en una actividad profesional".

15 Se refiere al artículo 15, apartado 1, del Reglamento (CE) núm. 44/2001 del Consejo, de 22 de diciembre de 2000, relativo a la competencia judicial, el reconocimiento y la ejecución de resoluciones judiciales en materia civil y mercantil (DOCE núm. 12, de 16 de enero de 2001, pp. 1-23, ref. DOUE-L-2001-80073).

16 Apartado 50.

17 Contra, apartado 46: "la regularidad de una actividad es uno de los elementos que deben tenerse en cuenta y no determina, por sí misma, la calificación que debe hacerse de una persona física con respecto al concepto de "profesional»". Son interesantes las consideraciones que hace al respecto María Victoria Cuartero Rubio: “PPuede ser el consumidor un profesional (del póker on-line)? A propósito del asunto Personal Exchange International, C-774/19”, en Boletín de Novedades CESCO, 20 de enero de 2021, donde concluye la autora (p. 6): “El criterio mismo de 'regularidad de la actividad' parece de compleja traslación al caso, porque si la actividad es jugar al póker, la clave para la delimitación no es tanto la regularidad de la actividad como la regularidad de las ganancias (concepto sensiblemente distinto del ánimo de lucro, compatible con la condición de consumidor). En fin, acaso estamos ante realidades novedosas resultantes de un mercado laboral y una actividad mercantil globales y distorsionados, que están alumbrando contratantes que no son el consumidor ortodoxo, pero tampoco el ortodoxo autónomo".

18 Recurso núm. 265/2016. 
Dicha condición de consumidor, por otro lado, no excluye la posibilidad de que el uso no profesional concurra con otros usos de naturaleza empresarial. Pensemos, por ejemplo, en la adquisición de un ordenador personal o de un dispositivo de telefonía móvil con el propósito de utilizarlo en el ámbito familiar. No es infrecuente en la práctica, y menos aún en tiempos de COVID-19 y teletrabajo ${ }^{19}$, que este uso familiar pueda compatibilizarse con la aplicación -más o menos esporádica- a determinadas finalidades profesionales, como podría ser el uso del equipo informático para celebrar una reunión de trabajo, o la utilización del móvil para llevar a cabo una comunicación profesional fuera del horario habitual.

Se trata de los denominados contratos con fines mixtos o con doble finalidad ${ }^{20}$, cuya tipicidad ha sido abordada por la STS núm. 224/2017, de 5 de abril21 (FD 4º), en los términos siguientes:

"1. Sobre esta noción de consumidor [en los contratos con doble finalidad], el problema que se plantea en este caso es si cabe considerar como tal a quien destina el bien o servicio a fines mixtos, es decir, a satisfacer necesidades personales, pero también a actividades comerciales o profesionales. Ni el art. 1 LGDCU ni el actual art. 3 TRLGDCU contemplan específicamente este supuesto, por lo que la doctrina y la denominada jurisprudencia menor han considerado que son posibles varias soluciones: que el contratante siempre es consumidor (pues a veces usa el bien o servicio para fines personales); que nunca lo es (ya que lo usa para fines profesionales); o que lo será o no en atención al uso preponderante o principal.

2. La Directiva 2011/83/UE, de 25 de octubre de 2011, sobre los derechos de los consumidores, que modificó las Directivas 93/13/CEE y 1999/44/CE, tampoco aborda expresamente este problema en su articulado. Pero en su considerando 17 aclara que, en el caso de los contratos con doble finalidad, si el contrato se celebra con un objeto en parte relacionado y en parte no relacionado con la actividad comercial de la persona y el objeto comercial es tan limitado que no predomina en el contexto general del contrato, dicha persona deberá ser considerada como consumidor.

Ante la ausencia de una norma expresa en nuestro Derecho nacional, resulta adecuado seguir el criterio interpretativo establecido en ese considerando de la Directiva, que además ha sido desarrollado por la jurisprudencia comunitaria. Así, en la STJCE de 20 de enero de 2005 \# (asunto C-464/01) se consideró que el contratante es consumidor si el destino comercial es marginal en comparación con el destino privado; es decir, no basta con que se actúe principalmente en un ámbito ajeno a la actividad comercial, sino que es preciso que el uso o destino profesional sea mínimo («insignificante en el contexto global de la operación de que se trate», en palabras textuales de la sentencia).

19. Vid. artículo 7.1.e) del Real Decreto-ley 21/2020, de 9 de junio, de medidas urgentes de prevención, contención y coordinación para hacer frente a la crisis sanitaria ocasionada por el COVID-19.

20. Vid. Manuel Jesús Marín López: "La condición de consumidor en los contratos con doble finalidad (personal y empresarial)", CESCO, 22 (2017): 197-206.

21 Recurso núm. 2783/2014. 
A su vez, la STJUE de 3 de septiembre de 2015 \#(asunto C-110/14) estableció: «El artículo 2, letra b), de la Directiva 93/13/CEE del Consejo, de 5 de abril de 1993, sobre las cláusulas abusivas en los contratos celebrados con consumidores, debe interpretarse en el sentido de que una persona física que ejerce la abogacía y celebra con un banco un contrato de crédito, sin que en él se precise el destino del crédito, puede considerarse «consumidor» con arreglo a la citada disposición cuando dicho contrato no esté vinculado a la actividad profesional del referido abogado. Carece de pertinencia al respecto el hecho de que el crédito nacido de tal contrato esté garantizado mediante una hipoteca contratada por dicha persona en su condición de representante de su bufete de abogado, la cual grava bienes destinados al ejercicio de la actividad profesional de esa persona, como un inmueble perteneciente al citado bufete».

En esta sentencia, el TJUE recuerda que, conforme al Derecho de la Unión, es consumidor toda persona física que, en los contratos regulados por la Directiva 93/13 /CEE, actúa con un propósito ajeno a su actividad profesional, y que, como tal consumidor, se encuentra en una situación de inferioridad respecto al profesional, idea que sustenta el sistema de protección establecido por la norma comunitaria. Y, al efecto de determinar la condición de consumidor del contratante, en el sentido de dicha Directiva, aclara el TJUE que el juez nacional debe tener en cuenta todas las circunstancias del caso susceptibles de demostrar con qué finalidad se adquiere el bien o el servicio objeto del contrato considerado y, en particular, la naturaleza de dicho bien o de dicho servicio.

Y el ATJUE de 19 de noviembre de 2015 \#(caso Tarcãu), en su apartado 27, recalcó: «A este respecto, procede recordar que el concepto de «consumidor», en el sentido del artículo 2, letra b), de la Directiva 93/13 tiene un carácter objetivo (véase la sentencia Costea, C-110/14, EU:C:2015:538, apartado 21). Debe apreciarse según un criterio funcional, consistente en evaluar si la relación contractual de que se trata se inscribe en el marco de actividades ajenas al ejercicio de una profesión».

3. En fin, para determinar si una persona puede ser considerada consumidor a los efectos de la Directiva 93/13/CEE y del TRLGCU, en aquellas circunstancias en las que existan indicios de que un contrato persigue una doble finalidad, de tal forma que no resulte claramente que dicho contrato se ha llevado a cabo de manera exclusiva con un propósito ya sea personal, ya sea profesional, el criterio del objeto predominante ofrece una herramienta para determinar, a través de un examen de la globalidad de las circunstancias que rodean al contrato -más allá de un criterio puramente cuantitativo- y de la apreciación de la prueba practicada, la medida en que los propósitos profesionales o no profesionales predominan en relación con un contrato en particular. De manera que, cuando no resulte acreditado claramente que un contrato se ha llevado a cabo de manera exclusiva con un propósito ya sea personal, ya sea profesional, el contratante en cuestión deberá ser considerado como consumidor si el objeto profesional no predomina en el contexto general del contrato, en atención a la globalidad de las circunstancias y a la apreciación de la prueba”.

De esta manera, el Tribunal Supremo da un marcado giro argumental respecto de la STJCE de 20 de enero de 2005 (asunto C-464/01) según la cual para ser consumidor no basta con que se actúe principalmente en un ámbito ajeno a la actividad comercial, sino que es preciso que el uso o destino 
profesional sea marginal o mínimo (“insignificante”) en comparación con el destino personal (v. gr.: no basta un $80 \%$ vs. $20 \%)^{22}$. El Tribunal Supremo, por el contrario, asume el criterio del fin predominante: "el contratante en cuestión deberá ser considerado como consumidor si el objeto profesional no predomina en el contexto general del contrato". Si se considera que "predominar" es prevalecer, preponderar, destacar, "ser más abundante en cantidad, número o intensidad" (DRAE), parece claro que el alto tribunal entiende ahora que, en los contratos con doble finalidad, se es consumidor cuando el fin personal predomina (es más del 50\%) sobre el fin empresarial o comercial de la adquisición, sin que sea preciso acreditar que éste sea mínimo o insignificante en el contexto global de que se trate ${ }^{23}$.

22. Vid., más recientemente, la STJUE de 25 de enero de 2018 (asunto C-498/16): "De lo anterior se desprende que, en principio, las reglas de competencia específicas de los artículos 15 a 17 del Reglamento n. ${ }^{\circ}$ 44/2001 solamente se aplican en el supuesto de que la finalidad del contrato celebrado entre las partes tenga por objeto un uso que no sea profesional del bien o servicio de que se trata (véase, en este sentido, la Sentencia de 20 de enero de 2005, Gruber, C-464/01, EU:C:2005:32, apartado 37). Por lo que respecta, más concretamente, a una persona que celebra un contrato para un uso que está relacionado parcialmente con su actividad profesional y que, por tanto, tan sólo es parcialmente ajeno a ésta, el Tribunal de Justicia ha considerado que podría ampararse en dichas disposiciones únicamente en el supuesto de que el vínculo de dicho contrato con la actividad profesional del interesado fuera tan tenue que pudiera considerarse marginal $y$, por tanto, sólo tuviera un papel insignificante en el contexto de la operación, considerada globalmente, respecto de la cual se hubiera celebrado el contrato (véase, en este sentido, la Sentencia de 20 de enero de 2005, Gruber, C-464/01, EU:C:2005:32, apartado 39)".

23. En esta materia no puede dejar de destacarse el pionero artículo 2 de la Ley de Cantabria 1/2006, de 7 de marzo, de Defensa de los Consumidores y Usuarios, que ofrece anticipadamente -vigente todavía la vieja LGDCU 26/1984- una solución al problema de los contratos con fines mixtos valorada de manera favorable por la doctrina especializada. Véase Sergio Cámara Lapuente: 'El concepto legal de 'consumidor' en el Derecho privado europeo y en el Derecho español: aspectos controvertidos o no resueltos”, Cuadernos de Derecho Transnacional (marzo 2011), vol. 3, n $1,90 \$ 9$, donde expone que la Ley 1/2006, de 7 marzo, de defensa de los consumidores de Cantabria no se limita a seguir la legislación estatal sino que -como excepción en el panorama nacional- "al reemplazar a la anterior Ley 6/1998, de 15 mayo, trató de aunar los criterios de la LGDCU con los de las Directivas comunitarias, a la par que introdujo algunos adverbios de enjundia y cuño doctrinal y comunitario, al disponer (art. 2) que '1. A los efectos de esta Ley, son consumidores y usuarios las personas físicas o jurídicas que adquieren, utilizan o disfrutan bienes y servicios en Cantabria, como destinatarios finales y con objetivos generalmente ajenos a cualquier actividad comercial o profesional. 2 . No tendrán la consideración de consumidores o usuarios quienes integren principalmente los bienes o servicios en un proceso de fabricación, comercialización o prestación dirigido al mercado, aun cuando dicha actividad no implique un lucro directo".

El propósito del artículo 2 de la Ley de Cantabria 1/2006 no era otro que poner a disposición de la Junta Arbitral de Consumo una herramienta apta para impedir el archivo automático de las reclamaciones resultantes de la aplicación del derogado, de 3 de mayo Real Decreto 636/1993 en el mismo momento en que un reclamante manifestara un uso profesional del bien o servicio de consumo, por esporádico o insignificante que resultara en el contexto de su uso global. Sobre esta cuestión, vid. también Jorge Tomillo Urbina: "Realidad y futuro del Sistema Arbitral de Consumo: una aproximación crítica desde la experiencia cántabra”, en Jorge Tomillo Urbina (dir.): Práctica Arbitral de Consumo, Thomson-Civitas, Cizur Menor, 2007: 42-43, y “El arbitraje de consumo en España: un recorrido histórico”, en Leticia García Villaluenga, Jorge Tomillo Urbina y Eduardo Vázquez de Castro (dirs.): Mediación, arbitraje y resolución extrajudicial de conflictos en el siglo XXI, ed. Reus SA, Madrid, 2010, tomo II: 96-98.

Lamentablemente e inexplicablemente, el texto original de la Ley 1/2006 fue modificado -once años más tarde- por el artículo 2 de la Ley de Cantabria 2/2017, de 24 de febrero, de Medidas Fiscales y Administrativas, que reproduce literalmente -de manera inútilmente seguidista- el artículo 3 TRLGDCU. Sobre esta extraña peripecia se pronuncia Joaquín Cayón de las Cuevas: La prestación de servicios sanitarios cit., pp. 195-196, observando cómo "en ocasiones, la brillantez se penaliza", para concluir: "[n]o acaba de comprenderse tal reforma, que supone una renuncia a que la legislación au- 


\section{IV.3. AJENIDAD Y PUBLICIDAD}

Respecto de la habitualidad, es de suma importancia matizar que para privar al adquirente no profesional de su condición jurídica de consumidor no basta con acreditar la repetición de conductas tendentes a la difusión publicitaria de las condiciones de venta. Muy al contrario, la jurisprudencia comunitaria establece que el hecho de que una persona ofrezca a la venta con publicidad bienes nuevos y usados, no excluye en modo alguno la necesidad de probar que dicha persona actúa, además, con un propósito relacionado con su actividad económica, negocio, oficio o profesión. Así se pronuncia la STJUE de 4 de octubre de 2018 (asunto C-105/17) 24: $^{4}$

"Por lo tanto, para considerar que la actividad de que se trata constituye una "práctica comercial», en el sentido de la referida disposición, procede comprobar que dicha actividad, por una parte, puede calificarse de "práctica de carácter comercial», es decir, que emana de un «comerciante», y, por otra, constituye una acción, omisión, conducta, manifestación o comunicación comercial «directamente relacionada con la promoción, la venta o el suministro de un producto a los consumidores» (véase, en este sentido, la sentencia de 17 de octubre de 2013, RLvS, C-391/12, EU:C:2013:669, apartado 37).

De lo antedicho resulta que solo puede considerarse que existe una "práctica comercial», en el sentido de la Directiva 2005/29, si la realiza un «comerciante», tal como se define en el artículo 2, letra b), de la citada Directiva.

Pues bien, procede recordar, como se ha precisado en el apartado 40 de la presente sentencia, que el mero hecho de que con la venta se persiga un ánimo de lucro o de que una persona física publique simultáneamente en una plataforma en línea una serie de anuncios en los que ofrece a la venta bienes nuevos y usados no basta por sí mismo, para calificar a esa persona de "comerciante» en el sentido de dicha disposición. Por lo tanto, una actividad como la controvertida en el litigio principal no puede calificarse de "práctica comercial» en el sentido del artículo 2, letra d), de la Directiva 2005/29.

Habida cuenta de las anteriores consideraciones, procede responder a la cuestión prejudicial planteada que el artículo 2, letras b) y d) de la Directiva 2005/29 y el artículo 2, punto 2, de la Directiva 2011/83, deben interpretarse en el sentido de que una persona física que publica simultáneamente en un sitio de Internet una serie de anuncios en los que ofrece a la venta bienes nuevos y usados, como la demandada en el litigio principal, solo debe calificarse de "comerciante» y tal actividad únicamente constituye una "práctica comercial» si dicha persona actúa con un propó-

tonómica de desarrollo module y complete aspectos huérfanos de solución jurídico-positiva en la legislación estatal". En su criterio, que comparto, "el problema de la reforma radica en un equivocado concepto constitucional de "legislación básica' que, antes de imponer la reproducción automática de los preceptos estatales, justamente permite el desarrollo y complemento del espacio que proporciona el legislador estatal" (p. 196, nota 125). Además -añado- también puede estar en la raíz del problema un desconocimiento no excusable de las líneas básicas de evolución normativa y jurisprudencial del Derecho de la UE en materia de protección jurídica de los consumidores.

24. ECLI:EU:C:2018:808. 
sito relacionado con su actividad económica, negocio, oficio o profesión, extremo que corresponde apreciar al órgano jurisdiccional remitente a la luz de todas las circunstancias pertinentes del caso de autos".

\section{IV.4. AJENIDAD Y AFIANZAMIENTO DE OPERACIONES} PROFESIONALES

Dentro de lo que hemos denominado prevalencia de la condición jurídica de consumidor en situaciones complejas, debemos considerar el frecuente supuesto de hecho constituido por aquellos contratos de fianza -a menudo solidaria y con renuncia a los beneficios de excusión y división- y de garantía inmobiliaria celebrados con una entidad de crédito por personas físicas que actúan con un propósito ajeno a su actividad profesional y que carecen de vínculos funcionales con la sociedad mercantil de la que se constituyen en garantes.

\section{IV.4.1. Incertidumbres Iniciales}

Algunas entidades de crédito, coherentes con una más que censurable laxitud ética ${ }^{25}$ y con el abuso sistemático a que han sometido a su confiada -o/y apurada- clientela a lo largo de las últimas décadas, se han resistido a aplicar la protección que a los adherentes no consumidores atribuye la Directiva 93/13/ $C E E$, de 5 de abril, sobre las cláusulas abusivas en los contratos celebrados con consumidores ${ }^{26}$, invocando la doctrina jurisprudencial del Tribunal Supremo en la que expresamente se excluye que las condiciones generales de los contratos suscritos con empresarios o profesionales (v.gr., una sociedad mercantil ${ }^{27}$ ) sean sometidas al segundo control de transparencia ${ }^{28}$ o control de transparencia específico para los

25. En alguna resolución jurisprudencial [Cfr. STS núm. 138/2015, de 24 de marzo (Recurso núm. 1765/2013)] se llega a hacer constar por el ponente que, ante la aplicación por los tribunales de la legislación comunitaria para la protección jurídica de los consumidores para paliar en la medida de lo posible los efectos devastadores producidos por las cláusulas abusivas bancarias en los últimos tiempos, alguna entidad de crédito -concretamente Cajasur- llegó a afirmar por escrito ["epistula enim non erubescit" (Marco Tulio Cicerón, Epistulae ad familiares, V, 12, 1] que "al declarar que las cláusulas sobre elementos esenciales del contrato pueden ser enjuiciadas a través del control de transparencia que asegure su comprensibilidad o comprensión real por el consumidor adherente, el Tribunal Supremo, en la citada sentencia núm. 241/2013, hace una labor de creación judicial del Derecho, que no está admitida en nuestro ordenamiento jurídico, y no una labor de hermenéutica jurídica, que es la única que podría realizar el órgano judicial”. Esto hizo que la Sala se viera obligada a precisar (FD 3․6) que “" no ha realizado una labor de 'creación judicial del Derecho' que exceda de su función de complemento del ordenamiento jurídico que le asigna el artículo 1.6 del Código civil, sino que ha interpretado la normativa interna a la luz de la letra y la finalidad de la Directiva 93/13/CEE, tal como esta ha sido interpretada por la jurisprudencia del TJUE".

26. DOCE núm. 95, de 21 de abril de 1993.

27. Cfr. artículo 2 del Real Decreto Legislativo 1/2010, de 2 de julio, por el que se aprueba el texto refundido de la Ley de Sociedades de Capital.

28. Sobre esta importante cuestión, en la que no es necesario insistir, sin embargo, al menos en esta sede sistemática, pueden verse, por todas, la STS núm. 241/2013, de 9 de mayo (ROJ STS 1916/2013), la STS núm. 464/2014, de 8 de septiembre (Recurso núm. 1217/2013), la STS núm. 677/2014, de 2 de diciembre (ROJ STS 5771/2014), la STS núm. 138/2015, de 24 de marzo (Recurso núm. 1765/2013), la STS núm. 222/2015, de 29 de abril (ROJ STS 2207/2015), o la STS núm. 705/2015, de 23 de diciembre (ROJ STS 5618/2015). Más recientemente, vid. la STJUE (Sala Cuarta) de 9 de 
contratos con consumidores, y en la que asimismo se excluye que a través de dicho segundo control de transparencia pueda efectuarse sobre tales cláusulas un control de abusividad ${ }^{29}$.

En los contratos de garantía no profesional de operaciones profesionales, la cuestión planteaba dudas e incertidumbres en la praxis jurisprudencial ${ }^{30}$ hasta el Auto TJUE (Sala Sexta) de 19 de noviembre de 2015 (asunto $C-74 / 15)^{31}$, que plantea la cuestión en los siguientes términos ${ }^{32}$ (apartados 23 a 25):

"[L]a Directiva 93/13 define los contratos a los que se aplica atendiendo a la condición de los contratantes, según actúen o no en el marco de su actividad profesional (véanse las sentencias Asbeek Brusse y de Man Garabito, C-488/11, EU:C:2013:341, apartado 30, así como Šiba, C-537/13, EU:C:2015:14, apartado 21).

Dicho criterio responde a la idea que sustenta el sistema de protección establecido por la referida Directiva, a saber, que el consumidor se halla en situación de inferioridad respecto al profesional, en lo referido tanto a la capacidad de negociación como al nivel de información, situación que le lleva a adherirse a las condiciones redactadas de antemano por el profesional sin poder influir en el contenido de éstas (véanse las sentencias Asbeek Brusse y de Man Garabito, C-488/11, EU:C:2013:341, apartado 31, así como Šiba, C-537/13, EU:C:2015:14, apartado 22).

Dicha protección es especialmente importante en el caso de un contrato de garantía o de fianza celebrado entre una entidad financiera y un consumidor. Tal contrato se basa, en efecto, en un compromiso personal del garante o del fiador de pagar la deuda asumida contractualmente por un tercero. Ese compromiso comporta para quien lo asume obligaciones onerosas, que tienen como efecto gravar su propio patrimonio con un riesgo financiero a menudo difícil de calibrar".

\section{IV.4.2. Certezas posteriores: el criterio de la ajenidad carente de vínculos funcionales.}

Desde esta perspectiva, el TJUE argumenta su posición favorable a la consideración prevalente de la condición jurídica de consumidor, con carácter general, en un contrato de garantía siempre y cuando concurra un doble requisito: a) que ese consumidor persona física actúe con un propósito ajeno a su actividad profesional y b) que carezca, además, de vínculos funcionales con la citada sociedad (aparta$\operatorname{dos} 26$ a 30$)$ :

julio de 2020 (asunto C-452/18), ECLI:EU:C:2020:536. En la doctrina, es de interés la obra de Francisco Javier Orduña Moreno, Carlos Sánchez Martín y Raquel Guillén Catalán: Control de transparencia y contratación bancaria, (Valencia: ed. Tirant lo Blanch, 2016), passim.

29 Para el caso de una sociedad limitada adherente, puede verse la STS núm. 314/2018, de 28 de mayo, Antecedente $3^{\circ} .1$ (ROJ STS 1901/2018).

30. Vid. Sheila Martínez Gómez: "Condición de no consumidor del fiador, persona física, que tiene vínculos funcionales con la mercantil deudora”, en Boletín de novedades CESCO, (24 de junio de 2020): 3 y ss.

31. ECLI:EU:C:2015:772.

$32 \mathrm{El}$ razonamiento viene reiterado en el Auto TJUE (Sala Décima) de 14 de septiembre de 2016 (asunto C-534/15) y en el Auto TJUE de 27 de abril de 2017 (asunto C-535/16). 
"En cuanto a si puede considerarse «consumidor», en el sentido del artículo 2, letra b), de la Directiva $93 / 13$, una persona física que se compromete a garantizar las obligaciones que una sociedad mercantil ha asumido contractualmente frente a una entidad bancaria en el marco de un contrato de crédito, procede señalar que si bien tal contrato de garantía o de fianza puede calificarse, en cuanto a su objeto, de contrato accesorio con respecto al contrato principal del que emana la deuda que garantiza [véase, en el contexto de la Directiva 85/577/CEE del Consejo, de 20 de diciembre de 1985, referente a la protección de los consumidores en el caso de contratos negociados fuera de los establecimientos comerciales (DO L 372, p. 31), la sentencia Dietzinger, C-45/96, EU:C:1998:111, apartado 18], se presenta como un contrato distinto desde el punto de vista de las partes contratantes, ya que se celebra entre personas distintas de las partes en el contrato principal. Por tanto, la calidad en la que las mismas actuaron debe apreciarse con respecto a las partes en el contrato de garantía o de fianza.

A este respecto, procede recordar que el concepto de "consumidor», en el sentido del artículo 2, letra b), de la Directiva 93/13 tiene un carácter objetivo (véase la sentencia Costea, C-110/14, EU:C:2015:538, apartado 21). Debe apreciarse según un criterio funcional, consistente en evaluar si la relación contractual de que se trata se inscribe en el marco de actividades ajenas al ejercicio de una profesión.

Corresponde al juez nacional que conozca de un litigio relativo a un contrato que pueda entrar dentro del ámbito de aplicación de la citada Directiva verificar, teniendo en cuenta todas las circunstancias del caso y el conjunto de las pruebas, si el contratante de que se trata puede calificarse de «consumidor» en el sentido de dicha Directiva (véase, en este sentido, la sentencia Costea, C-110/14, EU:C:2015:538, apartados 22 y 23 ).

De este modo, en el caso de una persona física que se constituyó en garante de la ejecución de las obligaciones de una sociedad mercantil, corresponde al juez nacional determinar si dicha persona actuó en el marco de su actividad profesional o por razón de los vínculos funcionales que mantiene con dicha sociedad, como la gerencia de la misma o una participación significativa en su capital social, o bien si actuó con fines de carácter privado.

Dadas estas circunstancias, procede responder a las cuestiones prejudiciales planteadas que los artículos 1, apartado 1, y 2, letra b), de la Directiva 93/13 deben interpretarse en el sentido de que dicha Directiva puede aplicarse a un contrato de garantía inmobiliaria o de fianza celebrado entre una persona física y una entidad de crédito para garantizar las obligaciones que una sociedad mercantil ha asumido contractualmente frente a la referida entidad en el marco de un contrato de crédito, cuando esa persona física actúe con un propósito ajeno a su actividad profesional y carezca de vínculos funcionales con la citada sociedad". 
En este mismo sentido se pronuncia la STS núm. 594/2017, de 7 de noviembre ${ }^{33}$, ocupándose de un caso en que la esposa era coprestataria y garante de las deudas mercantiles de su marido, contraídas en el ejercicio de la actividad empresarial que servía de sustento a la familia, cuyo régimen matrimonial era el de gananciales. También lo hace la STS núm. 314/2018, de 28 de mayo ${ }^{34}$ en relación con el único de los avalistas de un préstamo mercantil realizado por una entidad de crédito en favor de una sociedad mercantil en el que estima la concurrencia de la condición jurídica de consumidor por no ser socio ni administrador de la sociedad prestataria, lo que excluye la existencia de vínculo funcional con ésta ${ }^{35}$. En la misma línea se desenvuelve el razonamiento contenido en la Resolución de la Dirección General de los Registros y del Notariado de 13 de junio de $2019^{36}$, órgano directivo recientemente suprimido ${ }^{37}$ :

“[E]n la actualidad en el Derecho español [...] se entiende que la persona física que se constituye en garante de la ejecución de las obligaciones de una sociedad mercantil no tendrá la condición de «consumidor», en el sentido del artículo 2, letra b), de la Directiva 93/13, cuando el órgano judicial competente aprecie que tal garantía está relacionada con sus actividades comerciales, empresariales o profesionales o se concede por razón de los vínculos funcionales que mantiene con dicha sociedad, como ser socio, administrador o apoderado. En caso contrario, es decir, cuando el fiador actúa con fines de derecho privado, incluso aunque reúna la condición de pariente próximo de los administradores o socios de la mercantil, sí se le reconoce la condición de «consumidor» y toda la protección derivada de la misma.

En consecuencia, no resultando de la documentación presentada que la avalista se encuentre de alguna manera vinculada funcionalmente con los empresarios a quienes se concede el préstamo, debe reconocerse que tiene la condición de consumidora y, por tanto, que la normativa de protección de los consumidores es aplicable al contrato accesorio de aval'.

Esta posición aparece reiterada recientemente tanto en la STS núm. 307/2019, de 3 de junio ${ }^{38}$, excluyendo la condición de consumidor para un prestatario sociedad limitada, como en la STS núm. 203/2020, de 28 de mayo ${ }^{39}$ para una sociedad prestataria unipersonal que recibe un préstamo bancario coavalado solidariamente por el socio único y su esposa, que estaban casados en régimen legal de gananciales, aun desestimando in casu la concurrencia de ajenidad en la esposa:

33. Recurso núm. 3282/2014 (FD 4².2).

34. ROJ STS 1901/2018 (FD 5.6).

35. Ver también la Sentencia del Tribunal Constitucional núm. 75/2017, de 19 de junio, BOE núm. 171, de 19 de julio.

36. BOE núm. 163, de 9 de julio de 2019.

37. Cfr. el artículo 2.2 del Real Decreto 139/2020, de 28 de enero, por el que se establece la estructura orgánica básica de los departamentos ministeriales. Pasa a denominarse Dirección General de Seguridad Jurídica y Fe Pública ex artículo 7 del Real Decreto 453/2020, de 10 de marzo, por el que se desarrolla la estructura orgánica básica del Ministerio de Justicia, y se modifica el Reglamento del Servicio Jurídico del Estado, aprobado por el Real Decreto 997/2003, de 25 de julio.

38 ROJ STS 1727/2019 (FD 3º).

39 Recurso núm. 3120/2017 (FD 4.3). 
"No obstante, lo determinante es que la Sra. Angelina es cotitular del capital social de la compañia mercantil deudora. De tal manera que, aunque no hubiera firmado el préstamo como fiadora solidaria, al haberlo hecho su esposo, responde ganancialmente por la fianza de éste, como recogimos en la sentencia 594/2017, de 7 de noviembre [...]. Como consecuencia de ello, no puede predicarse respecto de la recurrente la ajenidad a la finalidad empresarial del préstamo que excluiría la vinculación funcional y permitiría reconocerle la cualidad legal de consumidora, conforme al art. 3 TRLGCU. Por lo que la sentencia recurrida no infringe dicho precepto".

En el mismo orden de cosas, la STS núm. 599/2020, de 12 de noviembre ${ }^{40}$ también aplica el criterio de prevalencia de la condición de consumidor en el primer pronunciamiento que realiza el alto tribunal sobre un supuesto de hecho en el que el régimen económico matrimonial no es el de gananciales, sino el de separación de bienes ${ }^{41}$. La doctrina que se establece es que " a falta de prueba sobre el consentimiento expreso de los cónyuges en [régimen de] separación de bienes para el ejercicio del comercio por sus respectivos cónyuges, no cabe negarles la condición legal de consumidores".

La citada sentencia ofrece, además, el valor añadido de sintetizar la doctrina de la Sala ${ }^{42}$ sobre el concreto problema de la vinculación funcional de los fiadores con el deudor principal a efectos de su calificación como consumidores:

40 ROJ STS 3631/2020 (FD 4º).

41 En el supuesto enjuiciado, los cónyuges estaban casados en régimen de separación de bienes conforme a la legislación civil catalana, por lo que resulta de aplicación el artículo 232-1 de la ley 25/2010, de 29 de julio, del libro segundo del Código Civil de Cataluña (CCC), relativo a la persona y la familia, pese a lo cual el Tribunal Supremo deja claro que "la competencia estatal exclusiva sobre legislación mercantil ampara la existencia de una normativa estatal sobre régimen económico matrimonial específica cuando uno de los cónyuges es comerciante, pues el concepto constitucional de legislación mercantil incluye la regulación del concepto de comerciante, su capacidad y su régimen de responsabilidad frente a terceros. De ello, se colige, a los efectos del caso que nos ocupa, que, en primer lugar, se aplican los arts. 6 a 12 CCom, con preferencia a las normas del Código Civil de Cataluña, que serán supletorias del Código de Comercio. No obstante, esta supletoriedad es de gran relevancia para la aplicación de tales arts. 6 y 9 CCom, en caso de régimen de separación de bienes, en cuanto que influyen en la determinación de qué bienes son propios del empresario comerciante y quedan sujetos a las resultas del comercio, $y$ cuáles son bienes propios de su cónyuge, por lo que, para quedar vinculados, se requerirá el consentimiento expreso de este. En lo que respecta a los bienes comunes, no son aplicables las presunciones de los arts. 7 y $8 \mathrm{CCom}$, en cuanto que están previstas para regímenes de comunidad, donde existe una comunidad de tipo germánico de los bienes gananciales. Cuando el régimen es el de separación de bienes catalán, los bienes en común lo son en comunidad tipo romana, por lo que, para vincularlos íntegramente a las resultas del comercio (en cuanto a la mitad indivisa del cónyuge no comerciante) es necesario el consentimiento de ambos cónyuges. Es decir, no bastaría el simple conocimiento al que se refiere la Audiencia Provincial, sino que se requeriría consentimiento expreso inscrito en el Registro Mercantil, a tenor del art. 11 CCom.” (FD 4‥5). Cfr., sobre esta cuestión, Lucía del Saz Domínguez: “Puede el fiador de una sociedad (cónyuge del administrador) invocar normas de protección al consumidor?”, en Boletín de novedades CESCO, (15 de diciembre de 2020), en cuyo criterio "la solución alcanzada por el Alto Tribunal (que considera consumidores a los fiadores cónyuges en régimen de separación de bienes de los administradores de la compañía -socios al 50\%-) no resulta exclusivamente aplicable a aquellos supuestos del Derecho Civil Especial de Cataluña, sino que también deberá aplicarse a los casos en que el régimen de separación de bienes se rija por nuestro Código Civil” (p. 6).

42. FD $3^{\circ} .2$. 
“De [las citadas] resoluciones previas podemos extraer las siguientes reglas:

a) Cuando el fiador es administrador o gerente de la persona jurídica deudora principal no puede tener la condición de consumidor, porque tiene vinculación funcional con dicha persona jurídica y, por tanto, con la operación financiera o crediticia.

b) Si el fiador tiene una participación significativa en la sociedad deudora, también tiene vinculación funcional y no puede ser consumidor.

c) Cuando el fiador es cónyuge en régimen de gananciales del deudor principal, tampoco es consumidor, porque responde de las deudas comunes y puede que participe de los beneficios de la sociedad en forma de dividendos, lo que supone vinculación funcional con la sociedad mercantil.

d) Cuando el fiador persona física no tiene cargo orgánico o societario alguno que le vincule con la sociedad deudora, no tiene una participación significativa en dicha sociedad, no responde de las deudas de su cónyuge en régimen de separación de bienes y no desempeńa actividad profesional relacionada con la operación afianzada, si puede tener la cualidad legal de consumidor".

\section{EQUIDAD Y TRANSPARENCIA EN LOS SERVICIOS DE INTERMEDIACIÓN EN LÍNEA}

Las consideraciones anteriores permiten llegar a la conclusión de que el concepto jurídico de consumidor, en tanto en cuanto atribuye tal condición merced a la posición "objetiva" que ocupa una persona en un contrato determinado de acuerdo con la naturaleza y finalidad de éste ${ }^{43}$, tiene una configuración jurisprudencial progresiva que implica la necesidad de realizar interpretaciones extensivas "pro consumatore", como ha manifestado expresamente la Resolución de la Dirección General de los Registros y del Notariado de 29 de septiembre de $2014^{44}$ :

"[S]e debe procurar una interpretación de las normas «pro consumatore», que impide la interpretación literal, como pretende el recurrente, sino que, contrariamente, ha de favorecer la información y por ende la protección del usuario de servicios financieros".

Esto es, sustancialmente, lo que hemos denominado principio de prevalencia de la condición jurídica de consumidor en situaciones complejas, caracterizadas básicamente por presentar algunas notas típicas de la actividad económica profesional compatibles, sin embargo, con la regla de la ajenidad desde una perspectiva global, es decir, en rango no suficiente para excluir la condición jurídica de consumidor en un adquirente de bienes y servicios ${ }^{45}$.

43. STS núm. 548/2018, de 5 de octubre (FD 2º Recurso núm. 265/2016.

44. BOE núm. 260, de 27 de octubre de 2014.

45. Ver supra, IV. 
Esta perspectiva reviste enorme interés si se tiene en cuenta que el Reglamento (UE) 2019/1150 se centra en la protección de los intereses legítimos de los usuarios profesionales ${ }^{46}$, y solo menciona de manera indirecta los propios de los consumidores de la UE (Considerando 2), sin perjuicio de la incidencia que en cuanto a estos últimos pueda tener, como veremos, la también reciente Directiva (UE) 2019/2161, del Parlamento Europeo y del Consejo, de 27 de noviembre de 2019, por la que se modifica la Directiva 93/13/CEE del Consejo y las Directivas 98/6/CE, 2005/29/CE y 2011/83/UE del Parlamento Europeo y del Consejo, en lo que atañe a la mejora de la aplicación y la modernización de las normas de protección de los consumidores de la Unión ${ }^{47}$.

El Reglamento tiene por objeto contribuir al correcto funcionamiento del mercado interior mediante el establecimiento de normas para asegurar que se conceden opciones apropiadas de transparencia, de equidad y de reclamación a los usuarios profesionales de servicios de intermediación en linea y a los usuarios de sitios web corporativos en relación con los motores de búsqueda en línea (art. 1.1). Y será de aplicación a los servicios de intermediación en línea y a los motores de buisqueda en linea que se faciliten o cuyo uso se proponga a los usuarios profesionales y los usuarios de sitios web corporativos, respectivamente, cuyo lugar de establecimiento o domicilio se sitúe en la Unión y que, por medio de servicios de intermediación en línea o motores de búsqueda en línea, ofrezcan bienes o servicios a los consumidores ubicados en la Unión, con independencia de dónde estén establecidos o residan los proveedores de dichos servicios y cualquiera que fuese la ley aplicable (art. 1.2). Esto incluye empresas de distinta naturaleza ${ }^{48}$, como plataformas de comercio electrónico como (Amazon, Marketplace, eBay); tiendas de aplicaciones (Apple App Store, Google Play Store); servicios de redes sociales para usuarios profesionales (páginas de Facebook); y comparadores de precios (Booking.com, Skyscanner). Las nuevas normas también serán aplicables a los motores de búsqueda como Google Search o Yahoo!, que se encargan de indexar las páginas web que los usuarios profesionales utilizan para ofrecer sus servicios a los consumidores.

46. Puede verse el interesante post de Martin Winner: "La regulación jurídica de los contratos celebrados a través de plataformas: el Derecho europeo", publicado en El Almacén de Derecho con fecha 26 de febrero de 2020, https://almacendederecho.org/la-regulacion-juridica-de-los-contratos-celebrados-a-traves-de-plataformas-el-derecho-europeo. Respecto del Reglamento 2019/1150, manifiesta el autor que "[e]l título indica que la normativa no intenta proteger a los consumidores sino a los comerciantes. El considerando (2) hace referencia a la dependencia de las empresas suministradoras (fabricantes) respecto de los titulares de las plataformas, y el mayor poder de negociación de éstos que les permitiría imponer sus condiciones a aquéllos. En otras palabras, el Reglamento considera que el proveedor de la plataforma ostenta una posición de dominio y, para evitar que abuse de su posición, prohíbe ciertas prácticas que considera, por ello, abusivas".

47. DOUE L 328, de 18 de diciembre de 2019.

48. https://www.garrigues.com/es_ES/garrigues-digital/la-ue-propone-incrementar-la-transparencia-de-las-plataformas-digitales. Para una clasificación de las plataformas de intermediación en línea en función de su modelo de negocio, vid. Matilde Cuena Casas: “La contratación” op. cit., pp. 302-304 \$\$ 51-55. 
El Reglamento se propone reforzar las obligaciones de transparencia relacionadas con la operativa de las plataformas en línea como prestadores de servicios de la sociedad de la información ${ }^{49}$. Para ello se dispone que los proveedores de servicios de intermediación en línea se asegurarán de que sus condiciones generales tendrán que ser de fácil acceso y comprensión para las empresas y los comerciantes que las utilicen. Concretamente, deberán estar redactadas de manera sencilla y comprensible, y encontrarse fácilmente disponibles para los usuarios profesionales en todas las etapas de la relación contractual con el proveedor de servicios de intermediación en línea, incluso en la fase precontractual [art. 3.1.a) y b)], y deberán explicar las razones en las que se basan las decisiones de suspender o cancelar, parcial o totalmente, sus servicios de intermediación terminar en línea a los usuarios profesionales [art. 3.1.c)], lo que incluye la retirada de un producto o servicio de las páginas de resultados de búsqueda.

Por otro lado, los servicios de intermediación en línea deberán informar acerca de los criterios que utilizan para determinar la clasificación de los productos, servicios y/o páginas webs de las empresas (art. 5), así como de la forma en que ofrecen sus propios bienes o servicios en su plataforma en comparación con los de otras empresas y comerciantes (art. 6). También deberán comunicar y motivar con claridad cualquier posible limitación a la libertad de sus usuarios profesionales para ofrecer mejores condiciones comerciales en otros entornos o plataformas (art. 7). La nueva normativa obligará asimismo a las plataformas dar a conocer cómo, quién y en qué condiciones podrá acceder a los datos que han generado los usuarios profesionales en sus plataformas en línea (art. 9).

Las normas anteriores vienen acompañadas por nuevos mecanismos para resolver de forma más rápida y eficaz los litigios que se produzcan entre las empresas y las plataformas en línea. El Reglamento exige que las grandes plataformas establezcan sistemas internos de tramitación de reclamaciones (art. 11). Además, todas las plataformas, grandes o pequeñas, deberán recurrir a mediadores imparciales e independientes para resolver estos conflictos por vía extrajudicial (art. 12). Por último, las nuevas normas permiten a las empresas que sean representadas ante los tribunales por asociaciones con el fin de exigir el cese de cualquier incumplimiento de las normas contenidas en el proyecto de Reglamento. También se pretende fomentar la adopción de códigos de conducta entre las plataformas en línea y los usuarios profesionales para asegurar la correcta aplicación de las nuevas normas (art. 17).

\section{LA CONDICIÓN JURÍDICA DE CONSUMIDOR -Y SU PREVALENCIA- EN LAS ADQUISICIONES DE BIENES Y SERVICIOS C2C INTERMEDIADAS POR PLATAFORMAS DIGITALES}

Aunque las recientes medidas comentadas pueden mejorar en alguna medida la protección jurídica de los consumidores que contratan con prosumers $^{50}$ a través de las plataformas digitales, no puede ocul-

49. En relación con las consecuencias jurídicas que se derivan de este presupuesto, especialmente de la aplicación de la Ley 34/2002, de 11 de julio, de Servicios de la Sociedad de la información y de comercio electrónico, cfr. Matilde Cuena Casas: “La contratación” op. cit., pp. 309-321 \$\$ 78-120.

50. El término prosumer es introducido por Alvin Toffler: La tercera ola, (trad. A. Martín), (Bogotá: ed. Plaza \& Janes 1980), 171 y ss. El texto original es The third wave, Bantam Books with William Morrows \& Co. Inc., New York: 1980: 264 y ss. 
tarse que, al menos en una primera aproximación, parece que el consumidor es el gran olvidado en un Reglamento importante, que repara en él de manera solo indirecta. Esta situación puede abordarse a la luz de algunas disposiciones específicas recientes, interpretadas desde la dimensión extensiva y prevalente que la jurisprudencia europea confiere a la condición jurídica de consumidor.

Parece claro, prima facie, que únicamente cuando nos encontremos ante un contrato subjetivamente vertical (B2C) cuyo elemento objetivo guarde relación directa con bienes o servicios de uso o consumo común, ordinario y generalizado, resultará aplicable plenamente la normativa prevista para la protección patrimonial de los consumidores y usuarios. Por eso reviste gran importancia la posición jurídica del adquirente no profesional que contrata con un proveedor no profesional (prosumer) a través de la intermediación de una plataforma de comercio on line.

En ese tipo de intercambios económicos de consumo colaborativo intermediado por plataformas digitales, resulta fundamental tener en cuenta que el particular proveedor está actuando fuera del cualquier ámbito de actividad empresarial o profesional, y puede procurar el bien o servicio a otro particular (C2C) o a un empresario o profesional (C2B). Por lo tanto, aun siendo las transacciones relativas a bienes o servicios de uso o consumo común, ordinario y generalizado, serán insuficientes para ofrecer la protección cualificada de la LGDCU -y del Derecho comunitario, en general- a un comprador que se relaciona contractualmente con un proveedor no profesional (C2C). Faltaría, pues, uno de los dos elementos estructurales (el elemento subjetivo) que exige la LGDCU para que los adquirentes no profesionales puedan beneficiarse de sus técnicas de protección.

En cuanto a las relaciones C2B (prosumer que suministra bienes y servicios a un empresario que actúa en el ámbito de su actividad empresarial o profesional), se ha afirmado que sigue existiendo una relación entre un consumidor y un profesional, donde el fundamento de la desigualdad jurídica, negociadora y económica seguirá vigente por lo que no existe exclusión legal de la concurrencia de la condición jurídica de consumidor este tipo de relaciones ${ }^{51}$, máxime teniendo en cuenta que el artículo 3 TRLGDCU no atiende a la posición que el consumidor tiene en la relación jurídica, es decir, si es o no proveedor de un bien o servicio ${ }^{52}$. Se trataría de una manifestación más del principio de prevalencia de la condición jurídica de consumidor en situaciones complejas, ya que las técnicas de protección jurídica específicamente previstas para tutela de la asimetría posicional de los consumidores no podrán invocarse por el comprador profesional.

\section{VI.1. APROXIMACIÓN NORMATIVA}

En este punto, es importante hacer entrar en juego la citada Directiva (UE) 2019/2161, de 27 de noviembre de 2019. El texto procede a la modificación de la Directiva 2011/83/UE, de 25 de octubre de

51. Sergio Cámara Lapuente: “El concepto legal” op. cit., p. 113-114 \$\$ 51.

52. Matilde Cuena Casas: “La contratación” op. cit., pp. 341-342 \$\$189-191. 
$2011^{53}$ introduciendo un importantísimo artículo 6 bis, con la finalidad de establecer un conjunto de "requisitos de información específicos adicionales para contratos celebrados en mercados en línea". Según este precepto, el proveedor del mercado en línea tiene la obligación de facilitar a los consumidores -sin perjuicio de lo dispuesto en la Directiva 2005/29/CE, de 11 de mayo de 200554-, antes de que éstos puedan perfeccionar y quedar obligados por un contrato a distancia, o cualquier oferta correspondiente, en un mercado en línea, información clara, comprensible y adecuada a las técnicas de comunicación a distancia con arreglo a las siguientes pautas:

a) Información general, facilitada en una sección específica de la interfaz en línea que sea fácil y directamente accesible desde la página en la que se presenten las ofertas, relativa a los principales parámetros que determinan la clasificación de las ofertas presentadas al consumidor como resultado de la búsqueda y la importancia relativa de dichos parámetros frente a otros parámetros [art. 6 bis 1.a)].

b) Información precisa acerca de si el tercero que ofrece los bienes, servicios o contenido digital es un comerciante o no, con arreglo a la declaración de dicho tercero al proveedor del mercado en línea [art. 6 bis 1.b)].

c) En el caso de que el tercero que ofrece los bienes, servicios o contenido digital no sea un comerciante, información clara, comprensible y adecuada acerca de que los derechos de los consumidores derivados de la legislación de la UE en materia de protección de los consumidores no son de aplicación al contrato [art. 6 bis 1.c)].

d) Información sobre la manera en que se reparten las obligaciones relacionadas con el contrato entre el tercero que ofrece los bienes, servicios o contenido digital y el proveedor del mercado en línea [art. 6 bis 1.d)].

Ello no es obstáculo (art. 6 bis 2) para que los Estados miembros puedan imponer otros requisitos de información adicionales a los proveedores de mercados en línea, siempre que se trate de medidas proporcionadas y no discriminatorias, y estén justificadas por razones de protección de los consumidores.

En otro orden de cosas, el artículo 5 de la Directiva (UE) 2019/2161 exige que se garantice a los ciudadanos que deseen obtener información sobre sus derechos como consumidores o conseguir la resolución extrajudicial de litigios, que puedan beneficiarse de un punto de entrada en línea, a través de la pasarela digital única establecida por el Reglamento (UE) 2018/1724 del Parlamento Europeo y del Consejo, de 2 de octubre de $2018^{55}$ que les permita:

53. DOUE L-304, de 2 de noviembre de 2011.

54. DOUE L-149, de 11 de julio de 2005.

55. DOUE L-295, de 21 de noviembre de 2018. 
a) Tener acceso a información actualizada sobre sus derechos como consumidores en la UE de forma clara, comprensible y fácilmente accesible.

b) Presentar una reclamación a través de la plataforma de resolución de litigios en línea creada en virtud del Reglamento (UE) 524/2013, de 21 de mayo de $2013^{56}$ así como acceder, en su casi, al centro competente de la Red de Centros Europeos del Consumidor, en función de las partes implicadas.

\section{VI.2. APROXIMACIÓN JURISPRUDENCIAL}

Además de la normativa comunitaria, también es relevante el papel desempeñado en este extremo por la jurisprudencia de la UE. Conviene destacar ahora la avanzada STJUE (Sala Quinta) de 9 de noviembre de 2016 (asunto $C-149 / 15)^{57}$, que aporta una respuesta muy útil y de gran solidez argumental al problema central de la confusión entre los conceptos de vendedor y de intermediario desde la óptica de los consumidores y de las consecuencias que ello puede producir en la realización efectiva del derecho que estos tienen a invocar para su protección la normativa de la Unión (apartados 37 a 42), partiendo de la base de que el conocimiento de la identidad del vendedor por parte del consumidor -y, especialmente, si se trata de un profesional o de un no profesional- es requisito imprescindible para que puede acceder a la protección jurídica que le corresponde:

"[E]n virtud del artículo 2, apartado 1, y del artículo 3 de la Directiva 1999/44, el vendedor está obligado a entregar al consumidor un bien que sea conforme con el contrato de compraventa y, en caso de que no lo sea, a repararlo o a sustituirlo, con arreglo al apartado 3 de esta última disposición. Así, el artículo 1, apartado 2, letra c), de la Directiva 1999/44 delimita el círculo de personas contra las que el consumidor puede actuar en ejercicio de los derechos que se derivan de esta Directiva. Por consiguiente, el conocimiento por parte del consumidor de la identidad del vendedor y, en especial, de su condición de particular o de profesional es imprescindible para que este último pueda disfrutar de la protección que la Directiva 1999/44 le confiere".

Por tanto, si $[\ldots]$ un profesional interviene como intermediario y por cuenta de un particular, el desconocimiento del consumidor sobre la calidad en la que el profesional interviene en la compraventa lo priva de los derechos que le garantiza la Directiva 1999/44, que, conforme a su artículo 7, apartado 1, son imperativos.

A este respecto, para garantizar una protección efectiva al consumidor en el marco de la Directiva 1999/44, resulta necesario que se informe al consumidor de que el propietario es un particular. Esta interpretación permite atribuir un efecto útil a la Directiva y es acorde con la jurisprudencia del Tribunal de Justicia, que considera que el sistema de protección establecido por las directivas de la Unión en materia de protección de los consumidores se basa en la idea de que el consumidor se halla en situación de inferioridad

56. DOUE L-165, de 18 de junio de 2013.

57. ECLI:EU:C:2016:840. 
con respecto al profesional en lo referente tanto a la capacidad de negociación como al nivel de información (sentencia de 4 de junio de 2015, Faber, C 497/13, EU:C:2015:357, apartado 42).

En efecto, en materia de información, existe un desequilibro considerable entre el consumidor y el intermediario profesional, especialmente cuando no se informa al consumidor de que el titular del bien vendido es, en realidad, un particular.

Por ello, en circunstancias como las del procedimiento principal, donde, habida cuenta del contexto en el que se efectúa la compraventa, el consumidor puede ser fácilmente inducido a error, debe atribuírsele un grado de protección reforzado. Por tanto, en virtud de la Directiva 1999/44, la responsabilidad del vendedor debe poder ser exigible al intermediario que crea un riesgo de confusión al dirigirse al consumidor, haciéndole creer que actúa en calidad de propietario del bien objeto de la compraventa.

La interpretación contraria, que excluiría en todo caso del ámbito de aplicación del artículo 1, apartado 2, letra c), de la Directiva 1999/44 al profesional que actúa como intermediario, se opone al objetivo global perseguido por la normativa de la Unión en materia de protección de los consumidores y consagrado en el artículo 169 TFUE, que consiste en garantizar un alto nivel de protección de los consumidores y, por tanto, en preservar su confianza”.

Como consecuencia de la argumentación expuesta, el TJUE declara que el concepto de "vendedor" contenido en el Derecho comunitario ${ }^{58}$ incluye al profesional que actúa como intermediario por cuenta de un no profesional sin informar debidamente al consumidor adquirente de que el propietario del bien vendido a través de la plataforma digital es un no profesional (prosumer):

"El concepto de «vendedor», conforme al artículo 1, apartado 2, letra c), de la Directiva 1999/44/CE del Parlamento Europeo y del Consejo, de 25 de mayo de 1999, sobre determinados aspectos de la venta y las garantías de los bienes de consumo, debe interpretarse en el sentido de que comprende también al profesional que actúa como intermediario por cuenta de un particular sin informar debidamente al consumidor adquirente de que el propietario del bien vendido es un particular, extremo que corresponde comprobar al órgano jurisdiccional remitente, tomando en consideración el conjunto de las circunstancias del caso. Esta interpretación no depende de si el intermediario percibe o no una remuneración por su intervención”.

\section{VI.3. LA PROTECCIÓN JURÍDICA DE LOS USUARIOS NO PROFESIONALES EN LOS SERVICIOS DE INTERMEDIACIÓN EN LÍNEA}

Lo anteriormente expuesto debe suscitar una reflexión acerca de la necesidad de proteger los derechos de los consumidores en la contratación con prosumers intermediada por las plataformas digitales.

58. Concretamente, en el artículo 1.2.c) de la Directiva 1999/44/CE del Parlamento Europeo y del Consejo, de 25 de mayo de 1999, sobre determinados aspectos de la venta y las garantías de los bienes de consumo (DOCE núm. 171, de 7 de julio de 1999). 
Sin perjuicio de reconocer los avances realizados en los últimos tiempos en el ámbito de la UE, no parece que esta actividad haya sido objeto todavía de una regulación completa y sistemática que sea consecuente con la situación de especial vulnerabilidad del adquirente no profesional.

\section{VI.3.1. La autenticidad de las reseńas de los clientes.}

Hay medidas que mejoran la protección jurídica de los consumidores mediante el control de la conducta de los suministradores, como puede ser el aseguramiento de la autenticidad de las reseñas de los clientes ${ }^{59}$, cuyos efectos reputacionales son sin duda valorados positivamente por los consumidores. Es la práctica de los usuarios, es muy habitual tomar como referencia para el acceso a bienes o servicios las reseñas que los clientes van colocando en los sitios web más frecuentados. Por esta razón, cuando se afirma que las reseńas de un producto son ańadidas por consumidores que han utilizado o adquirido realmente el producto con carácter previo, reflejando sus experiencias, el titular de la plataforma debe haber tomado medidas razonables y proporcionadas para comprobar que dichas reseñas pertenezcan a tales consumidores ${ }^{60}$, absteniéndose en todo caso de añadir o encargar a otra persona física o jurídica que añada reseñas o aprobaciones de consumidores que sean falsas, así como de distorsionar reseñas de consumidores o aprobaciones sociales con el fin de promocionar productos.

\section{VI.3.2. Información sobre la existencia de decisiones automatizadas que permiten personalizar los precios.}

También se ha avanzado en la protección jurídica de los consumidores en relación con la controvertida cuestión de los precios personalizados, especialmente delicada cuando se utilizan indicadores de la disposición individual a pagar del consumidor ${ }^{61}$. Se asume que los comerciantes pueden personalizar el precio de sus ofertas para determinados consumidores o determinadas categorías de consumidores basándose en la toma de decisiones automatizada y la elaboración de perfiles del comportamiento de los consumidores, lo que permite a los comerciantes evaluar el poder adquisitivo del consumidor.

La consecuencia inmediata es la naturaleza fluctuante de los precios y la extraordinaria rapidez con que se producen algunas mutaciones, relacionadas además con el historial de comportamiento del

59. Artículo 7.6 de la Directiva 2005/29/CE, de 11 de mayo de 2005, introducido por el artículo 3.4.c) de la Directiva (UE) 2019/2161, de 27 de noviembre de 2019: "Cuando un comerciante facilite el acceso a las reseñas de los consumidores sobre los productos, se considerará esencial la información acerca de si el comerciante garantiza que las reseñas publicadas pertenezcan a consumidores que hayan realmente utilizado o adquirido el producto".

60. Anexo I.23.ter y quater de la Directiva 2005/29/CE, introducido por el Artículo 3.7.b) de la Directiva (UE) 2019/2161 dentro del catálogo de prácticas comerciales desleales por engañosas.

61. Artículo 6.e bis) de la Directiva 2011/83/UE, introducido por el artículo 4.4.a).ii de la Directiva (UE) 2019/2161. Observa Martin Winner: "La regulación jurídica de los contratos celebrados a través de plataformas", cit., que "los indicadores de la disposición a pagar son indirectos y a veces muy crudos, como el tipo de ordenador usado, pero también pueden basarse en las compras precedentes". También manifiesta Matilde Cuena Casas: "La contratación" cit., p. $344 \$$ 197 que "la oferta personalizada dificulta la comparación con otras ofertas y la clasificación de las ofertas puede ser opaca". 
cliente, con sus preferencias -proyectadas y publicadas en ocasiones a través de uso de redes sociales-, con sus hábitos y con su disposición a pagar determinados niveles de precios. Pero, a cambio, cuando el precio que se ofrezca a los consumidores esté personalizado en función de una toma de decisión automatizada, se les debe informar claramente de ello (transparencia), a fin de que puedan tener en cuenta los riesgos potenciales de su decisión de compra ${ }^{62}$.

Queda pendiente de abordar la espinosa cuestión de la utilización de datos personales no facilitados voluntariamente para elaborar los perfiles del consumidor en los algoritmos de búsqueda ${ }^{63}$, y su aplicación en orden a ofrecer productos o servicios con carácter alternativo a los que vayan asociados precios superiores en función de su disposición a satisfacer otro rango de precios.

\section{VI.3.3. Información sobre la identidad profesional del oferente y el reparto de las obligaciones contractuales con el proveedor del mercado en línea}

Con todo lo anterior, era necesario, sin embargo, ir un poco más allá. Es evidente que, como hemos dicho, se ha dado un paso decisivo en la buena dirección con la Directiva (UE) 2019/2161, al introducir un artículo 6 bis en la Directiva 2011/83/UE obligando al proveedor del mercado en línea a facilitar al consumidor -antes de que quede obligado por un contrato a distancia- información clara y comprensible sobre un hecho capital: si el tercero que ofrece los bienes, servicios o contenido digital es un comerciante o no, con arreglo a la declaración de dicho tercero al proveedor del mercado en línea, por lo que no bastará hacerlo en las condiciones generales, sino que tendrá que realizarse de manera más llamativa y visible ${ }^{64}$. Esta obligación de información se extiende a advertir, en los casos en que el tercero que ofrece los bienes no sea comerciante, que los derechos de los consumidores derivados del Derecho de la UE en materia de protección de los consumidores no son de aplicación al contrato, y comprende también la necesidad de indicar el reparto de las obligaciones relacionadas con el contrato entre el tercero oferente (prosumer) y el proveedor del mercado en línea.

De este modo, se refuerza de manera estimable la transparencia en las operaciones intermediadas por plataformas digitales, poniendo a disposición del consumidor los datos necesarios para la toma de decisiones informadas de compra, con conocimiento específico de que la práctica de determinadas transacciones digitalizadas no va acompañada del acceso a los instrumentos jurídicos de protección para quienes actúan en los mercados con un propósito ajeno a cualquier actividad empresarial, comercial o profesional.

62. Directiva (UE) 2019/2161, considerando (45).

63. Puede verse la Commission Decision of 26.4.2018 on setting up the group of experts for the Observatory on the Online Platform Economy, con especial atención al elenco de tareas detalladas en su artículo 2; COM (2018) 2393 final.

64. Cfr. Martin Winner: "La regulación jurídica de los contratos celebrados a través de plataformas" cit. 


\section{VI.3.4. La responsabilidad contractual del titular de la plataforma por ocultación de información}

Sin demérito alguno de la utilidad que pueden proporcionar las medidas que acabamos de citar, así como la adopción y aplicación de códigos de conducta por los proveedores de servicios de intermediación en línea ${ }^{65}$, el principio de prevalencia de la condición jurídica de consumidor en situaciones complejas encontraría mejor salvaguarda con el grado de protección reforzado al que se refiere la citada STJUE (Sala Quinta) de 9 de noviembre de 2016 (asunto C-149/15) como justificación de su pronunciamiento ${ }^{66}$ ratio decidendi en el sentido de que "la responsabilidad del vendedor debe poder ser exigible al intermediario que crea un riesgo de confusión al dirigirse al consumidor, haciéndole creer que actúa en calidad de propietario del bien objeto de la compraventa".

Sabemos que las relaciones contractuales horizontales de naturaleza no profesional (C2C) excluyen la aplicación de los derechos de los consumidores en la Unión Europea, que tienen como presupuesto la verticalidad (B2C) de la relación contractual. Se trata de un acervo jurídico de extraordinaria importancia, en el que se integran, sin ánimo de enumeración exhaustiva, el principio de conformidad de los bienes con el contrato, la prestación de garantía legal o convencional, los derechos de información ordinarios y cualificados, el derecho de desistimiento, los derechos específicos asociados a los contratos a distancia y a los contratos celebrados fuera del establecimiento, los plazos de entrega al cliente, la prohibición del cargo de tasas por la utilización de determinados medios de pago, las especialidades en la transmisión del riesgo por daños fortuitos, la limitación del coste (tarifa básica) de las comunicaciones telefónicas o el reembolso de pagos adicionales no consentidos.

Todos estos derechos se fundamentan en la vulnerabilidad del consumidor derivada de su asimetría posicional respecto del profesional de la actividad económica en el mercado, por lo que son aplicables únicamente en el contexto de las relaciones verticales B2C. Y el acceso a los mismos por parte del usuario no profesional podría reconstruirse extendiendo la responsabilidad contractual al titular de la plataforma, al menos en determinados supuestos, con lo que se verticalizaría en la práctica la relación contractual entre proveedor y adquirente no profesionales.

Es necesario tener en cuenta que el adquirente no profesional a través de las plataformas digitales de intermediación no solo está en una situación asimétrica respecto de los proveedores de servicios de la sociedad de la información y a los proveedores profesionales usuarios, sino que también lo está normalmente en relación con los proveedores no profesionales usuarios de las plataformas digitales (prosumers). Y aquí es justamente donde debemos retomar el principio de la prevalencia de la ajenidad en situaciones complejas o, cuando menos, su espíritu normativo proteccionista, unido al sistema de valores patrocinado por la Unión Europea, que integra desde su fundación el objetivo de garantizar a

65. Artículo 17 del Reglamento (UE) 2019/1150.

66. Apartado 41. 
los consumidores "un alto nivel de protección"67, desarrollado ahora a través de la Agenda del Consumidor Europeo y el Programa plurianual de Consumidores para 2014-202068.

En este sentido, cuando el titular de la plataforma incumple la obligación de informar al consumidor acerca de la identidad de la parte contratante, es decir, en aquellos casos en que aquél no aclara si el consumidor contrata con el propio titular de la plataforma o con un tercero y, en este último supuesto, si el tercero oferente tiene o no la condición de profesional, parece razonable que el titular de la plataforma asuma las obligaciones contractuales de un proveedor con carácter general y, muy especialmente, cuando no solo es prestador del servicio de la sociedad de la información, sino también del servicio profesional intermediado ${ }^{69}$. De este modo, una plataforma de intermediación de servicios de transporte de pasajeros -v.gr.: Uber- debería responder de las diferentes patologías del cumplimiento contractual, incluidos los daños personales que pueden sufrir los pasajeros ${ }^{70}$.

Situados en este punto, el fundamento de la responsabilidad no estaría tanto en la irregularidad ejecutiva del suministrador no profesional, cuanto en el incumplimiento por parte del titular de la plataforma de su obligación de informar acerca de a) la naturaleza no profesional del oferente y b) de la correlativa inaplicabilidad de las técnicas de protección jurídica de los consumidores previstas en el acervo comunitario. Para el cumplimiento de esta obligación, el titular de la plataforma debe atenerse a lo que el proveedor le comunique. Consecuentemente, el titular de la plataforma no está obligado a verificar la información ${ }^{71}$. Podría haberse pensado en proteger al adquirente estableciendo, cuando menos, una obligación de declarar directamente su condición a cargo del propio proveedor no profesional. No se ha hecho así en las más recientes reformas del Derecho de la Unión, quizá no solamente por facilitar a las plataformas beneficiarse de una reducción de costes, sino porque, en la práctica, quizá permita asegurar más fácilmente el cumplimiento de la obligación de informar ${ }^{72}$ ya que si el proveedor no proporciona motu proprio la información sobre su condición, el titular de la plataforma puede -y debe- bloquearle el acceso a ésta.

67. Artículo 169.1 del Tratado de Funcionamiento de la Unión Europea (TFUE), DOUE C-83, de 30 de marzo de 2010. 68. Reglamento (UE) 254/2014 del Parlamento Europeo y del Consejo, de 26 de febrero de 2014, sobre el Programa plurianual de Consumidores para el período 2014-2020, DOUE L-84 de 20 de marzo de 2014. Vid. Amy McGourty, Mariusz Maciejewski y Christina Ratcliff: "La política de los consumidores: principios e instrumentos", en Fichas temáticas sobre la Unión Europea. Parlamento Europeo, diciembre de 2020. https://www.europarl.europa.eu/factsheets/es/sheet/46/ la-politica-de-los-consumidores-principios-e-instrumentos

69. Vid. supra, nota 2.

70. Sobre estas cuestiones, vid., con carácter general, Araya Alicia Estancona Pérez: Transporte terrestre de pasajeros, ed. Tirant lo Blanch, Valencia, 2018: 131 y ss.

71. El Considerando (28) de la Directiva 2019/2161 establece: "De conformidad con el artículo 15, apartado 1, de la Directiva 2000/31/CE del Parlamento Europeo y del Consejo, los proveedores de mercados en línea no deben estar obligados a comprobar la situación jurídica de los terceros suministradores. En cambio, los proveedores de mercados en línea deben exigir a los terceros suministradores que indiquen su condición de comerciantes o no comerciantes a efectos de la legislación en materia de protección de los consumidores, y que les proporcionen esta información".

72. Martin Winner: "La regulación jurídica de los contratos celebrados a través de plataformas" cit. 
En efecto, no debe perderse de vista que esta información tiene carácter sustancial de cara a tipificar su ocultación -o su plasmación de manera poco clara, ininteligible, ambigua o en un momento que no sea el adecuado, o que no dé a conocer el propósito comercial de la práctica en cuestión en caso de que no resulte evidente por el contexto- como conducta engañosa del titular de la plataforma ${ }^{73}$ que haga o pueda hacer que el consumidor medio tome una decisión sobre una transacción que de otro modo no hubiera tomado, configurándose como una práctica comercial desleal $\Gamma^{4}$.

Se trata, en resumidas cuentas, de una cuestión de transparencia que resulta extrapolable a otros ámbitos sensibles, v.gr. la obligación de ofrecer información actualizada, sencilla y comprensible sobre los parámetros principales que rigen la clasificación y el funcionamiento de los algoritmos de búsqueda ${ }^{75}$, sin que llegue a exigirse a los proveedores de los servicios de intermediación en línea ni a los proveedores de motores de búsqueda en línea revelar algoritmos o información que, dentro de un grado de certeza razonable, podría inducir a error a los consumidores o causarles un perjuicio mediante la manipulación de los resultados de las búsquedas; o también la obligación impuesta al proveedor de servicios de intermediación en línea de informar en sus condiciones generales acerca de si entre los indicados parámetros principales figura la posibilidad de que los usuarios profesionales o los usuarios de sitios web corporativos influyan en la clasificación remunerando directa o indirectamente al proveedor correspondiente para priorizar su aparición en los motores de búsqueda.

\section{VI.3.5. La responsabilidad contractual del titular de la plataforma por influencia decisiva sobre las condiciones prestacionales}

En último término, debe ponerse de manifiesto la conveniencia de que los Estados miembros hagan uso de la vía abierta por el muy reciente y tantas veces citado artículo 6 bis.2, en orden a introducir otras disposiciones adicionales aplicables a los proveedores de mercados en línea, siempre que sean proporcionadas, no discriminatorias, y estén justificadas por razones de protección a los consumidores. En este sentido, habría que valorar la introducción de la responsabilidad del titular de la plataforma digital por incumplimiento contractual del prestador si el consumidor puede confiar razonablemente en que aquélla ejerce una influencia decisiva sobre las condiciones de las prestaciones efectuadas por los proveedores no profesionales ${ }^{76}$.

73. Artículo 7.4.f) de la Directiva 2005/29/CE, de 11 de mayo de 2005, introducido ex novo por el artículo 3.4.a).ii de la Directiva (UE) 2019/2161, de 27 de noviembre de 2019.

74. Cfr., sobre este particular, Julio Álvarez Rubio: La protección del consumidor en el Derecho de la competencia, ed. Comares, Granada, 2017: 54 y ss.

75. Artículo 5 del Reglamento (UE) 2019/1150, de 20 de junio de 2019.

76. Este planteamiento está recogido en la STJUE (Gran Sala) de 20 de diciembre de 2017 (asunto C-434/15), apartado 39. Sobre el tema puede verse una referencia en Martin Winner: "La regulación jurídica de los contratos celebrados a través de plataformas" cit., que menciona un Borrador de discusión de una Directiva sobre mercados en línea elaborado en 2016 por el Research Group in the Law of Digital Services, en cuyo artículo 18.1 (Liability of the platform operator for non-performance of suppliers) se establece: "If the customer can reasonably rely on the platform operator having a predominant influence over the supplier, the platform operator is jointly liable with the supplier for non-performance of the supplier-customer contract". También se ofrecen en el Borrador algunos indicadores que permiten la presunción de influencia decisiva, como puede ser la exclusividad de la plataforma como mecanismo de contratación proveedor-clien- 
Dentro de las incógnitas que plantea una tecnología de última generación aplicada a procesos económicos y sociales novedosos sobre los que todavía no hay demasiada información, y sin desconocer la conveniencia de fomentar el desarrollo de las plataformas digitales en la Unión Europea, esta puede ser una de las vías a explorar próximamente por los Estados miembros para el establecimiento en sus ordenamientos internos de las medidas adicionales aplicables a los proveedores de mercados en línea, a las que se refiere el artículo 6 bis.2 de la Directiva 2011/83/UE, introducido por el artículo 4.5 de la Directiva (UE) 2019/2161.

En esta línea, es de interés hacer referencia a la Nueva Agenda del Consumidor ${ }^{77}$ para el período 2020-2025. En este documento ${ }^{78}$ se contiene cumplida referencia a la transformación digital, estableciendo como punto de partida que:

"La transformación digital está cambiando de forma radical las vidas de los consumidores, brindándoles más oportunidades y ofreciéndoles una mayor variedad de bienes y servicios. Al mismo tiempo, puede hacer que les resulte más difícil tomar decisiones informadas y proteger sus intereses. La recopilación y el tratamiento de los datos correspondientes en combinación con el análisis del comportamiento de los consumidores y de sus sesgos cognitivos pueden utilizarse para influir en ellos y hacer que tomen decisiones que pueden ir en contra de sus intereses. Esto puede limitar la eficacia de las normas actuales diseñadas para proteger a los consumidores en el entorno digital, entre otras cosas, contra las prácticas comerciales desleales".

Desde esta perspectiva, la Comisión entiende que la protección jurídica de los consumidores europeos en este entorno pasa por acometer una serie de reformas imprescindibles:

"Deben abordarse las prácticas comerciales que pasan por alto el derecho de los consumidores a tomar decisiones informadas, hacen un uso fraudulento de sus sesgos de comportamiento o distorsionan sus procesos de toma de decisiones. Estas prácticas incluyen el uso de patrones «oscuros», determinadas prácticas de personalización que a menudo se basan en la elaboración de perfiles, la publicidad encubierta, el fraude, la información falsa o engañosa y los comentarios manipulados de consumidores. Se requieren orientaciones adicionales sobre la aplicabilidad de los instrumentos de Derecho en materia de protección de los consumidores, tales como la Directiva sobre las prácticas comerciales desleales y la Directiva sobre los derechos de los consumidores, a estas prácticas. En última instancia, los consumidores deben gozar de un nivel de protección y equidad en linea comparable al que tienen fuera de línea.

te, la determinación por el titular de la plataforma de los términos del contrato proveedor-cliente, la determinación de precios, la retención de pagos, el ofrecimiento de una imagen uniforme de todos los suministradores en torno a la marca del titular, el marketing enfocado en el titular de la plataforma o la monitorización por el titular de la conducta de los proveedores (art. 18.2). Puede consultarse su texto completo en EuCML, Issue 4 (2016): 164-169.

77. Comunicación de la Comisión al Parlamento Europeo y al Consejo. Nueva Agenda del Consumidor. Reforzar la resiliencia del consumidor para una recuperación sostenible, (Bruselas: 13 de noviembre de 2020. COM (2020) 696 final.

78. Epígrafe 3.2. 
A fin de garantizar que los consumidores aprovechen al máximo el considerable potencial de la transformación digital, sus intereses deben tenerse en cuenta en la concepción y la adaptación de las normas que regulan la economía digital. Se persigue un doble objetivo: crear un espacio digital más seguro para los consumidores, en el que sus derechos estén protegidos, y garantizar unas condiciones de competencia equitativas que faciliten la innovación para ofrecer servicios mejores y más novedosos a todos los europeos.

En primer lugar, la próxima propuesta de la Comisión para una nueva norma sobre servicios digitales estará encaminada a definir nuevas y mayores responsabilidades y a reforzar la rendición de cuentas de los intermediarios y las plataformas en linea. La norma sobre servicios digitales garantizará que los consumidores estén protegidos de forma eficaz contra los productos, los contenidos y las actividades ilícitos en las plataformas en línea de la misma manera que lo están fuera de línea.

En segundo lugar, a fin de abordar los problemas que surgen en los mercados digitales propensos a deficiencias, como el poder de ciertas plataformas digitales para limitar el acceso, la Comisión prevé presentar asimismo una norma sobre mercados digitales. Combinaría la regulación ex ante de las plataformas digitales que tienen la capacidad de limitar el acceso con un marco de investigación dinámica de mercado para examinar los mercados digitales propensos a deficiencias. Los consumidores serán los beneficiarios finales de unos mercados digitales más justos y de acceso más irrestricto, incluidos unos precios más bajos, mejores y nuevos servicios y una mayor variedad de mercado".

También se plantea la Nueva Agenda del Consumidor para el período 2020-2025 actualizar la normativa existente en un buen número de materias de extraordinaria relevancia. Se cita, en primer término, la seguridad de productos de consumo no alimentarios, habida cuenta del cambio producido en la manera de manifestarse los riesgos existentes o, incluso, en la aparición de nuevos riesgos desconocidos hasta ahora, especialmente en las compras a operadores ubicados fuera de la Unión Europea. Se atiende, en segundo término, a la gestión por parte de los consumidores del acceso y utilización de sus datos personales a través de una identidad electrónica universalmente aceptada. En tercer lugar, se plantea la necesidad de abordar el bloqueo geográfico injustificado, mecanismo discriminatorio entre los consumidores por segmentar mercados a lo largo de las fronteras nacionales. En cuarto lugar, se observa la necesidad de impulsar decididamente la Estrategia Europea de Datos para crear un verdadero mercado único de datos y de espacios comunes de datos. En quinto lugar, en fin, se hace referencia a la necesidad de contar con una eficaz regulación de medidas de protección ante las nuevas tendencias introducidas por la transición digital en la oferta de productos y servicios financieros por prestadores no tradicionales, como las empresas tecnofinancieras o los prestamistas inter pares (préstamos de alto costo a corto plazo, soluciones de pago instantáneo):

"El uso de categorias alternativas de datos, en combinación con la toma de decisiones automatizadas sobre la calificación crediticia, plantea dudas con respecto a qué datos deben utilizarse para evaluar la solvencia de los consumidores y destaca los riesgos de discriminación derivados de las decisiones basadas en algoritmos opacos — un tipo de riesgo que probablemente también se aborde a través del acto jurídico antes mencionado sobre los requisitos para la inteligencia artificial—. Además, debe revisarse la legislación 
existente, como la Directiva sobre crédito al consumo, la Directiva de crédito hipotecario, la Directiva sobre las cuentas de pago y la Directiva sobre comercialización a distancia de servicios financieros, a fin de reflejar el creciente uso de los medios digitales y abordar los desafíos antes mencionados. Debe facultar a los consumidores para entender los productos y comparar y aceptar ofertas en linea, impulsando así la innovación y la confianza de los consumidores. El nuevo paquete de finanzas digitales de la Comisión, incluidas las estrategias de finanzas digitales y de pagos minoristas y las propuestas legislativas sobre los criptoactivos y la resiliencia operativa digital del sector financiero, tiene por objeto garantizar que los consumidores y las empresas obtengan los beneficios de la innovación a la vez que están protegidos. Reflejar los avances en curso en materia de transformación digital también formará parte de la estrategia de inversión minorista, que debe centrarse en los intereses de los inversores individuales y está prevista para la primera mitad de 2022".

Estamos, desde luego, ante una sugerente oportunidad para aprovechar eficazmente el impulso de las instituciones europeas de cara a colmar los retos y objetivos que hemos puesto de relieve en las páginas precedentes, mejorando la protección de los consumidores frente a los riesgos que comporta el acceso a la prestación de servicios a través de las plataformas de intermediación on line.

\section{REFERENCIAS}

- Alfaro Águila-Real, Jesús. "La sentencia Uber del TJUE”. Publicado en El Almacén de Derecho (20 de diciembre de 2017).

- Álvarez Rubio, Julio. La protección del consumidor en el Derecho de la competencia. Granada: ed. Comares 2017.

- Cámara Lapuente, Sergio. “El concepto legal de 'consumidor' en el Derecho privado europeo y en el Derecho español: aspectos controvertidos o no resueltos". Cuadernos de Derecho Transnacional, vol. 3, no 1 (2011): 84-117

- Cayón de las Cuevas, Joaquín. La prestación de servicios sanitarios como relación jurídica de consumo. Navarra: Cizur Menor:Thomson Reuters, ed. Civitas, 2017.

- Cuartero Rubio, María Victoria. “¿Puede ser el consumidor un profesional (del póker on-line)? A propósito del asunto Personal Exchange International, C-774/19”. Boletín de Novedades CESCO, (20 de enero de 2021).

- Cuena Casas, Matilde. "La contratación a través de plataformas intermediarias en línea”. Cuadernos de Derecho Transnacional vol. 12, no 2 (octubre 2020): 283-348. https://doi.org/10.20318/cdt.2020.5612 
- Del Saz Domínguez, Lucía. “¿Puede el fiador de una sociedad (cónyuge del administrador) invocar normas de protección al consumidor?”. Boletín de novedades CESCO, (15 de diciembre de 2020).

- $\quad$ Ertz, Myriam, Durif, Fabien. y Arcand, Manon. "Collaborative consumption: conceptual snapshot at a buzzword”. Journal of Entrepreneurship Education, 19.2 (2016): 1-3 https://doi.org/10.2139/ssrn.2799884

- $\quad$ Estancona Pérez, Araya Alicia. Transporte terrestre de pasajeros. Valencia: ed. Tirant lo Blanch, 2018.

- Gomá Garcés, Ignacio y Ojeda Baños, Pablo. "HD Joven: a propósito de la reciente sentencia del TJUE sobre Uber”. Hay Derecho, 16 de febrero de 2018.

- Levin, Jonathan D. “The economics of internet markets". National Bureau of Economic Research, Massachusetts, 2011. https://doi.org/10.3386/w16852

- $\quad$ Amy McGourty, Mariusz Maciejewski y Christina Ratcliff. "La política de los consumidores: principios e instrumentos". Fichas temáticas sobre la Unión Europea. Parlamento Europeo, diciembre de 2020.

- Marín López, Manuel Jesús. "La condición de consumidor en los contratos con doble finalidad (personal y empresarial)”. CESCO, 22 (2017): 197-206.

- Martínez Gómez, Sheila. "Condición de no consumidor del fiador, persona física, que tiene vínculos funcionales con la mercantil deudora”. Boletín de novedades CESCO, (24 de junio de 2020).

- Orduña Moreno, Francisco Javier, Sánchez Martín, Carlos. y Guillén Catalán, Raquel. Control de transparencia y contratación bancaria. Valencia: ed. Tirant lo Blanch, 2016.

- $\quad$ Reyes López, María José. "La reforma introducida en el TRLGDCU por Ley 3/2014 sobre el derecho de desistimiento e información". Actualidad Jurídica Iberoamericana, 2 (2015).

- $\quad$ Nick Srnizek. Platform Capitalism. Cambridge (UK)/Malden, MA (USA). Polity Press, 2017.

- Toffler, Alvin. La tercera ola, (trad. A. Martín). Bogotá:1980. ed. Plaza \& Janes Texto original: The third wave, Bantam Books with William Morrows \& Co. Inc., New York, 1980. 
- Tomillo Urbina, J. "Realidad y futuro del Sistema Arbitral de Consumo: una aproximación crítica desde la experiencia cántabra”. Tomillo Urbina, J. (dir.): Práctica Arbitral de Consumo, Navarra: Cizur Menor: ed. Thomson-Civitas, 2007.

- Tomillo Urbina, J. “El arbitraje de consumo en España: un recorrido histórico”. García Villaluenga, Leticia, Tomillo Urbina, Jorge. y Vázquez de Castro, Eduardo. (dirs.): Mediación, arbitraje y resolución extrajudicial de conflictos en el siglo XXI. Madrid: 2010, ed. Reus, SA, tomo II: 81-115. https://doi.org/10.1893/011.081.0404

- Winner, Martin. "La regulación jurídica de los contratos celebrados a través de plataformas: el Derecho europeo". El Almacén de Derecho, (26 de febrero de 2020).

RECIBIDO: $16 / 02 / 2021$

APROBADO: 22/05/2021 